INRA Prod. Anim., 2017, $30(1), 3-18$

\title{
Modifications ciblées des génomes : apports et impacts pour les espèces d'élevage
}

\author{
A. DUCOS, B. BED'HOM', H. ACLOQUE ${ }^{\prime}$, B. PAIN ${ }^{3}$ \\ ${ }^{\prime}$ GenPhySE, Université de Toulouse, INRA, INPT, INP-ENVT, 31320, Castanet Tolosan, France \\ ${ }_{2}$ GABI, AgroParisTech, INRA, Université Paris-Saclay, 78350, Jouy-en Josas, France \\ ${ }_{3}$ Univ Lyon, Université Lyon 1, INSERM, INRA, Stem Cell and Brain Research Institute, \\ CSC USC1361, 69675, Bron, France \\ Courriel : a.ducos@envt.fr
}

La technique CRISPR-Cas9 permet de modifier les génomes de façon fine et efficace. Elle ouvre de nouvelles perspectives pour le développement de lignées d'animaux génétiquement modifiés. Si des applications a priori intéressantes sont envisagées dans les filières de productions animales, notamment dans le domaine de la santé, ces nouvelles techniques posent également de nombreuses questions d'ordre scientifique, éthique, réglementaire, économique et stratégique ${ }^{1}$.

Les premières souris transgéniques ont été produites dès le début des années 1980 par micro-injection de matériel génétique exogène dans l'un des pronoyaux d'œufs fécondés (Gordon et Ruddle 1981). La même technique a été utilisée, quelques années plus tard, pour produire les premiers animaux d'élevage génétiquement modifiés, mammifères (lapins, moutons et porcs; Hammer et al 1985), ou poissons (saumon, truite et carpe notamment; Zhang et al 1990, Du et al 1992). En revanche, les spécificités de l'embryon des espèces aviaires ont nécessité le recours à d'autres techniques, comme l'infection rétro- et lentivirale d'embryons à des stades précoces du développement, pour obtenir les premiers poulets transgéniques à la fin des années 1980 (Bosselman et al 1989, Salter et Crittenden 1989, Nishijima et Iijima 2013).

Entre autres limites, ces méthodes « historiques » de transgénèse présentent l'inconvénient majeur de ne maîtriser ni les sites d'insertion des transgènes, ni le nombre de copies effectivement intégrées dans le génome des cellules ciblées (Essalmani et al 2000), rendant les profils d'expression des transgènes généralement peu prédictibles. Par exemple, des effets de position peuvent fortement influencer la transcription des transgènes (Clark et al 1994). Chez la souris, la pos- sibilité de modifier le génome de façon précise par Recombinaison Homologue (RH) dans des cellules Embryonnaires Souches (ES) a été démontré dès 1989 (Capecchi 1989) et a constitué une avancée scientifique majeure pour la recherche en biologie. La manipulation des cellules ES reste cependant impossible dans la plupart des espèces de mammifères d'élevage, et non pertinente chez le poulet car elle ne permet pas la transmission des modifications génétiques à la lignée germinale (Nishijima et Iijima 2013, Schusser et al 2013).

Des approches alternatives ont donc été recherchées et proposées. Chez les mammifères, des modifications ciblées de cellules somatiques en culture par $\mathrm{RH}$, suivies de clonage par transfert de noyaux («somatic cell nuclear transfer », ou SCNT) ont été réalisées. Les premiers résultats probants ont été obtenus chez le mouton et publiés dès 2000 (Mc Creath et al 2000). Cependant, cette approche demeure longue, fastidieuse, et d'une efficacité limitée. Chez le poulet, l'utilisation de la RH dans des cellules germinales primordiales en culture (PGC) a permis de produire les premiers animaux recombinants pour un locus défini d'immunoglobuline, mais avec une efficacité là encore limitée (1 clone cellulaire modifié pour $10^{7}$ cellules transfectées ; Schusser et al 2013).
Une possibilité d'améliorer cette efficacité de façon importante est apparue avec le concept de « nucléases programmables ", permettant de générer des cassures double-brin au niveau de régions précises de la séquence d'ADN (voir la synthèse de Chandrasegaran et Carroll 2016). Les premières techniques basées sur ce concept («Zinc Finger Nucleases » ou ZFN en 1996, «Transcription Activator-Like Effector Nuclease » ou TALEN en 2010), malgré leur efficacité avérée, sont toutefois d'utilisation délicate, du fait notamment de la complexité de leur élaboration et de leur coût élevé. Une avancée décisive a eu lieu avec le développement de la technique CRISPR-Cas9 (Jinek et al 2012), beaucoup plus simple en termes de conception et d'utilisation, moins coûteuse, et, de ce fait, bien plus accessible (Jo et al 2015). À ce jour, son efficacité a été démontrée dans plus de 40 espèces (Haeussler et Concordet 2016), et ses perspectives d'utilisation sont considérables (Hsu et al 2014).

Dans la suite de cet article, nous présenterons les principes généraux de cette méthode d'ingénierie ciblée des génomes, considérée par d'aucuns comme une révolution dans le monde de la biologie (Ledford 2015a, Lander 2016). Ses applications en recherche fondamentale et médicale, en ingénierie écologique

${ }^{1}$ Un extrait de cette revue sera présenté lors des Journées de la Recherche Avicole et Palmipèdes à Foie Gras (Tours) le 6 avril 2017. 
ou dans certains domaines industriels particuliers (pharmacie, biotechnologies blanches...) seront évoquées brièvement, avant de présenter plus longuement son utilisation à des fins agronomiques (filières de productions animales). Les limites de cette technique, les questions qu'elle soulève (aspects éthiques, réglementaires, économiques ...) seront également présentées et discutées.

\section{1 / Présentation de la tech- nique CRISPR-Cas 9}

\section{1 / CRISPR-Cas9 : un système immunitaire bactérien}

CRISPR est l'acronyme de « Clustered Regularly Interspersed Short Palindromic Repeats $»$ : séquences répétées palindromiques courtes (30 bases) regroupées et régulièrement intercalées avec d'autres séquences qualifiées de "spacers", vestiges de séquences de bactériophages ou de plasmides, d'environ 36 bases. Ce type particulier de motif a été observé dès la fin des années 1980 dans le génome d'Escherichia coli, puis, rapidement, dans de nombreuses autres espèces de bactéries et d'archées. L'évolution des connaissances dans ce domaine est bien résumée par Lander (2016). Des gènes codant des protéines aux fonctions variées (hélicases, exonucléases...) ont été identifiés à proximité de ces séquences CRISPR. Ces gènes "Cas », pour "CRISPRassociated genes ", dont le gène Cas9, sont directement liés à la fonction de ces système biologiques (immunité adaptative chez les procaryotes, voir la synthèse de Marraffini 2015).

\section{2 / CRISPR-Cas9 : un outil révolutionnaire d'ingénierie ciblée des génomes}

Les travaux de microbiologie moléculaire ont permis des progrès importants dans notre compréhension du fonctionnement de ces systèmes. Cependant, si CRISPR-Cas9 induit une telle effervescence depuis quelques années dans la communauté scientifique, et bien audelà, c'est en raison de son utilisation possible pour générer des cassures au niveau de régions très précises de l'ADN, dans potentiellement tout type de cellules : animales, végétales, microbiennes. L'idée initiale de " détourner » ce système bactérien pour en faire un outil d'ingénierie ciblée des génomes, ainsi que les premières preuves de concepts, sont à porter au crédit de plusieurs scientifiques très médiatisés ces derniers temps, comme, d'une part, le tandem Emmanuelle Charpentier et Jennifer Doudna (Doudna et Charpentier 2014), et, d'autre part, Feng Zhang (Zhang
2015). Ces chercheurs et leurs institutions respectives s'opposent frontalement depuis quelques années pour revendiquer la paternité du système (« guerre des brevets », Ledford 2016). Cette opposition, qui atteint des proportions inédites, pourrait avoir des conséquences sur les utilisations scientifiques et commerciales futures de ces systèmes (Egelie et al 2016).

\section{a) CRISPR-Cas 9 : principes généraux}

Le principe général de l'outil CRISPRCas9 est relativement simple, et schématisé sur la figure 1. Comme c'était déjà le cas pour ZFN ou TALEN, CRISPRCas9 est constitué de deux composants principaux : un dispositif (ou domaine) de « guidage », permettant la reconnaissance par hybridation d'une séquence cible sur le génome de la cellule à modifier, et un domaine de " clivage » enzymatique, générant des cassures doublebrin de la molécule d'ADN au niveau de la (ou des) région(s) ciblée(s) (on parle de « ciseaux moléculaires »).

Deux éléments principaux différencient CRISPR-Cas9 des systèmes antérieurs ZFN et TALEN. Le premier est la nature du dispositif de guidage. Dans le cas de CRISPR-Cas9, ce dispositif est constitué d'une simple molécule d'ARN guide, ou sgRNA, dont une partie permet l'association à l'enzyme Cas9, et une vingtaine de bases sont complémentaires de la séquence cible. Dans le cas de ZFN ou TALEN, le dispositif de guidage est un complexe protéique, plus difficile à produire. L'autre élément de différenciation est la nature de l'enzyme associée au dispositif de guidage : Cas9 dans le cas des premiers systèmes CRISPR, Fok I dans le cas de ZFN ou TALEN.
La première Cas9 avait été obtenue à partir de Streptococcus pyogenes. Aujourd'hui, de nouvelles nucléases similaires sont identifiées, comme la protéine Cas9 de Staphylococcus aureus, qui est plus courte, donc plus facile à délivrer aux cellules (Ran et al 2015), ou les enzymes Cpf1 d'Acidaminococcus et Lachnospiraceae (Zetsche et al 2015), élargissant la palette d'outils utilisables par les chercheurs. Les systèmes CRISPRCas9 sont globalement plus simples et plus rapides à développer et à tester que ZFN ou TALEN. Comme l'illustrent certains exemples détaillés plus loin, ils sont aussi sensiblement plus efficaces et offrent la possibilité de « multiplexage » (modification simultanée de plusieurs cibles du génome), ce qui était beaucoup plus difficile à envisager avec ZFN ou TALEN (Bao et al 2016).

Dans le processus de modification ciblée par les nucléases programmables, une fois la cassure double-brin générée au niveau de la (des) séquence(s) cible(s), deux voies de réparation par la cellule sont possibles (figure 2). La première (NHEJ, pour « Non Homologous End Joining ", ou ligation non-homologue des extrémités) consiste en un simple ajout ou excision de bases sur chacun des brins à l'endroit de la coupure. Si cette dernière est induite au niveau d'une région codante (gène), les courtes insertions/délétions générées par la réparation (un à quelques nucléotides) induisent classiquement un décalage du cadre de lecture (mutation «frameshift ») conduisant à l'inactivation, ou "knock-out» $(\mathrm{KO})$, de ce gène. L'autre voie de réparation (HDR, pour « Homology Directed Repair », ou réparation par recombinaison homologue) est possible si un modèle d'ADN est apporté à la cellule

Figure 1. Principe général de la technique CRISPR-Cas9 : l'enzyme induisant des cassures double-brin (Cas9) est dirigée vers une séquence très précise de l'ADN cible par l'intermédiaire d'un ARN guide.

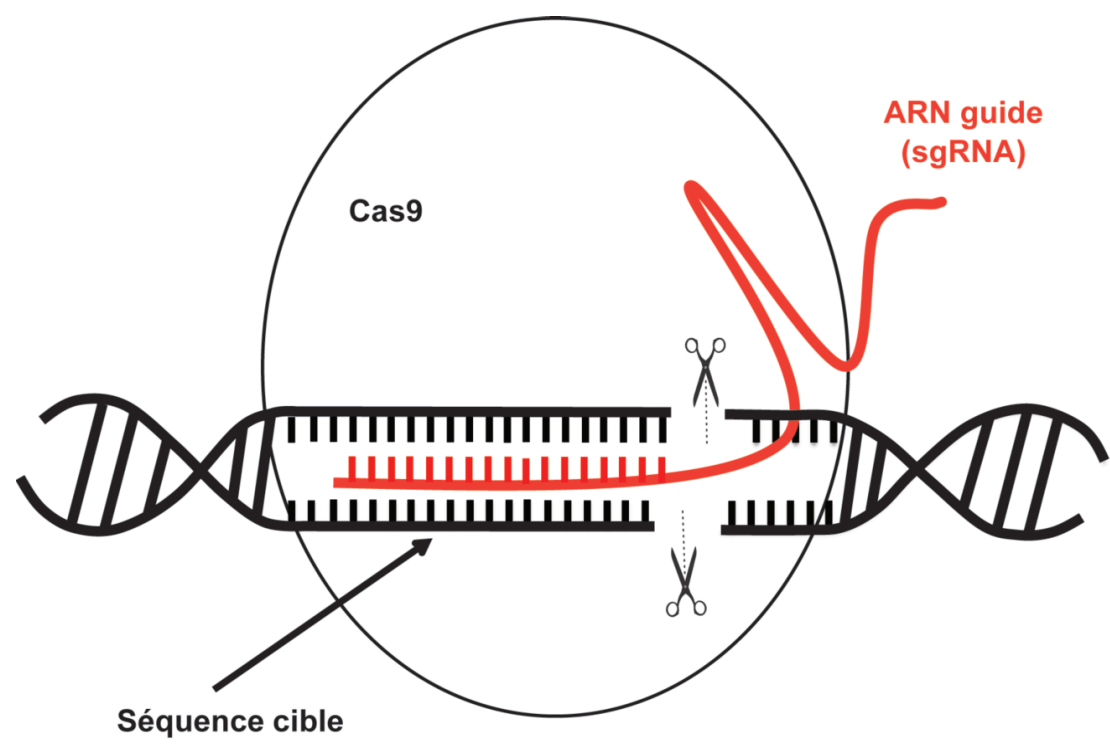


Figure 2. Mécanismes de réparation de la cassure double-brin (d'après Maxmen 2015).

A) Réparation de la cassure double-brin par non-homologous end joining (NHEJ) : cette voie de réparation induit des insertions/délétions au niveau du point de cassure : si celui-ci est situé dans un gène, le résultat peut être son inactivation (knock-out, ou KO).

B) Réparation de la cassure double-brin par homology directed repair (HDR) : cette voie de réparation permet l'insertion, à l'endroit de la cassure double-brin, d'une séquence "modèle ", par des mécanismes de recombinaison homologue ; elle permet d'induire une (des) fonction(s) nouvelle(s) au niveau de la cellule (knock-in, ou $\mathrm{KI})$.

A

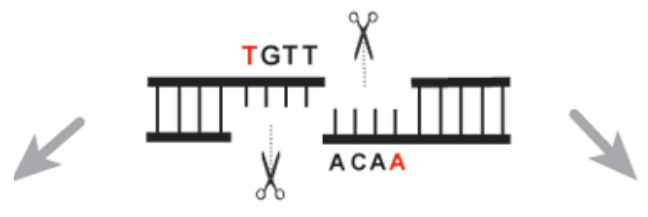

Ajout de quelques nucléotides
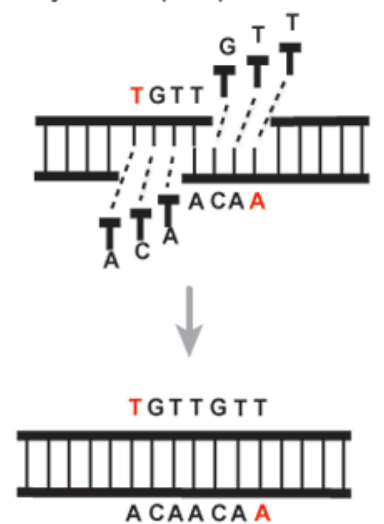

ACAACA A ou

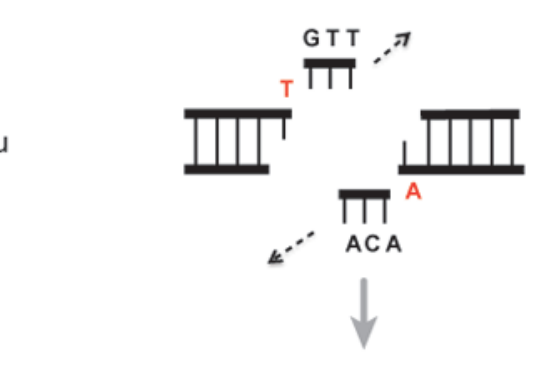

Insertions-Délétions

(Knock-out : KO)
Excision de quelques nucléotides

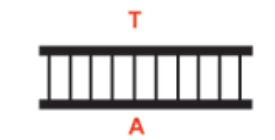

B

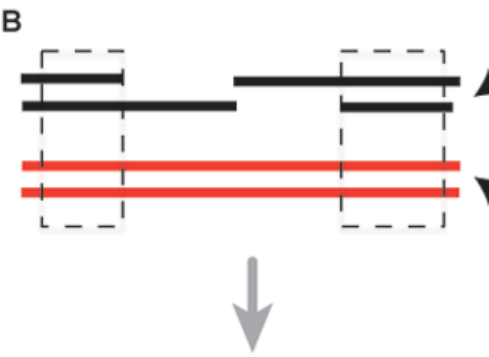

Molécule d'ADN originale ciblée par CRISPR-Cas9 (cassure double-brins)<smiles>C1=CC[CH-]1</smiles>

I I Régions d'homologie

Fragment d'ADN modèle (template) apporté à la cellule

Les brins d'ADN cassés sont réparés en recopiant l'information apportée par le fragment d'ADN modèle

Le modèle se sépare, laissant la molécule d'ADN originale avec une nouvelle séquence (provenant du modèle) à l'endroit de la cassure (knock-in : KI)

en même temps que le système CRISPRCas9. Il peut s'agir d'un gène de la même espèce, avec, par exemple, une variation de séquence intéressante, ou un gène d'une autre espèce. Ce modèle
L'efficacité de CRISPR-Cas9 est supérieure, voire très supérieure, à celle des systèmes antérieurs (Wang et al 2016). Elle est le plus souvent élevée pour générer des $\mathrm{KO}$ de gènes (voie de réparation NHEJ). Elle est en revanche généralement moindre pour réaliser des KI, les évènements de recombinaison homologue restant assez rares, et pouvant par ailleurs s'accompagner d'insertions/ délétions indésirables (Paquet et al 2016). Des efforts de recherche importants sont actuellement réalisés pour tenter d'améliorer l'efficacité (le rendement) des modifications KI (par la voie HDR). L'utilisation d'inhibiteurs de la voie de réparation concurrente (NHEJ) est une piste explorée avec un certain succès par différents groupes de recherche (voir par exemple Chu et al 2015 ou Maruyama et al 2015).

b) CRISPR-Cas 9 : stratégies de procréation d'individus génétiquement modifiés

Les composants du système CRISPRCas9 peuvent être délivrés dans les cellules à modifier (cellules somatiques en culture, cellules souches pluripotentes induites, ou iPS, cellules embryonnaires...) de différentes façons : i) à l'aide de vecteurs viraux ; ii) par électroporation ou micro-injection de plasmides d'expression, de transposons ou d'ARN messager ; iii) à l'aide de systèmes physiques (nanoparticules) ; voir pour plus de détails les revues de Ran et al (2013a), Jo et al (2015), Sato et al (2016), et Komor et al (2017).

Les mammifères génétiquement modifiés ont été principalement produits, jusqu'à présent, à l'aide des stratégies suivantes : i) micro-injection pronucléaire dans des embryons produits par fécondation in vitro, suivie du transfert des embryons modifiés dans des femelles receveuses ; cette stratégie impose de vérifier la présence des modifications souhaitées chez les descendants, et peut conduire à des cas de mosaïcisme ; ii) modification de cellules somatiques en culture, sélection (criblage) des clones cellulaires ayant les modifications souhaitées, et production d'animaux modifiés à partir de ces cellules par SCNT (voir pour plus de détails la revue de Menchaca et al 2016).

Chez le poulet, les PGC (« primordial germ cells ») constituent un matériau de choix pour la procréation d'individus génétiquement modifiés (Schusser et al 2013). Ces cellules, précurseurs des gamètes, présentent la particularité de migrer, via la circulation sanguine, du croissant germinal jusqu'aux crêtes génitales, et colonisent les gonades en formation (Doran et al 2016). Elles peuvent être collectées, soit à partir du sang 
circulant d'un embryon de deux jours, soit à partir des gonades embryonnaires (6-8 jours de développement), et utilisées pour initier des cultures cellulaires à long terme. Ces PGC en culture peuvent être génétiquement modifiées, puis réinjectées au troisième jour d'incubation dans la circulation sanguine d'autres embryons. Ceci permet de générer des individus chimériques $(\mathrm{G} 0)$, utilisés pour produire des descendants $(\mathrm{G} 1, \mathrm{G} 2 \ldots)$ ayant intégré la (ou les) modification(s) dans l'ensemble de leurs cellules, à l'état hétérozygote $(\mathrm{G} 1)$ ou homozygote $(\mathrm{G} 2)$ (van de Lavoir et al 2006, Nishijima et Iijima 2013). Une approche encore plus simple, consistant à transfecter directement les PGC in vivo, a été récemment proposée et validée par Tyack et al (2013). Elle permet de s'affranchir des délicates étapes de culture cellulaire et ouvre des perspectives intéressantes, notamment pour les espèces aviaires autres que le poulet (Doran et al 2016). Cependant, avec ce type d'approche, le contrôle des évènements de modification ne peut se faire qu'au niveau de l'animal, comme dans le cas de la micro-injection pronucléaire chez les mammifères. Le criblage des modifications souhaitées est donc plus difficile qu'à partir d'une culture cellulaire.

Chez les poissons, la technique la plus communément utilisée jusqu'à présent est la micro-injection dans des embryons au stade 1-4 cellule(s).

\section{2 / Utilisations de la technique CRISPR-Cas 9}

\section{1 / Panorama général}

Le caractère révolutionnaire de la technologie CRISPR-Cas9 tient notamment au spectre extrêmement large de ses applications, déjà testées ou potentielles. Celles-ci sont bien décrites dans Doudna et Charpentier 2014, Hsu et al 2014, ou Ledford 2015a.

CRISPR-Cas9 est, avant tout, un outil de plus en plus incontournable en recherche fondamentale, permettant d'aborder de nouvelles questions scientifiques, ou de s'intéresser à d'autres, plus anciennes, de façon plus efficace et/ou approfondie (voir la synthèse au tableau 1). CRISPR-Cas9 permet, par exemple, d'étudier efficacement les relations génotype-phénotype via la réalisation de cribles fonctionnels (perte ou gain de fonction) à haut débit (voir la revue de Shalem et al 2015). L'utilisation de formes désactivées de Cas9 (dCas9), ayant perdu la faculté de couper l'ADN, mais pouvant toujours s'associer à des régions précises par l'intermédiaire du sgRNA, est par ailleurs devenue une méthode de choix pour visualiser des régions génomiques particulières au sein de cellules vivantes (dCas9 fusionnée avec des protéines fluorescentes ; Ma et al 2015). Ces formes désactivées dCas 9 constituent aussi des outils extrêmement précis et souples pour étudier les mécanismes de régulation de l'expression génique. Mandegar et al 2016, par exemple, ont récemment montré que la fusion de dCas9 avec un domaine de répression KRAB permettait d'inhiber de façon spécifique et réversible l'expression de gènes dans des cellules iPS (CRISPR-based interference, ou CRISPRi). Le même principe peut être mis en œuvre pour étudier les mécanismes de régulation mettant en jeu des phénomènes épigénétiques (dCas9 couplée à des modulateurs épigénétiques, par exemple des enzymes méthyltransférases ; " epigenome editing », voir la synthèse de Kungulovski et Jeltsch 2016).

CRISPR-Cas9 ouvre également des perspectives extrêmement importantes dans le domaine de la thérapie génique et cellulaire humaine, en facilitant les modifications de cellules somatiques, iPS, voire embryonnaires : élimination ou correction de variations délétères ou pathologiques, addition de gènes thérapeutiques (voir la revue de Maeder et Gerbach 2016). Des travaux permettant d'améliorer la précision et l'innocuité de ces approches sont néanmoins nécessaires pour ce type d'application. Ceci fait actuellement l'objet de très gros efforts de recherche, qui visent notamment à réduire les modifications « horscibles » (voir par exemple Doench et al 2016, Kleinstiver et al 2016, Paquet et al 2016 ou la revue de Komor et al 2017), à introduire spécifiquement des modifications homozygotes ou hétérozygotes (Paquet et al 2016), ou à améliorer l'efficacité et l'innocuité des vecteurs utilisés pour délivrer le système de modification aux cellules (Nelson et Gerbach 2016). Une nouvelle méthode permettant de modifier de façon irréversible des bases uniques de l'ADN, $\mathrm{C}$ vers T ou $\mathrm{G}$ vers $\mathrm{A}$ ( « base editing »), sans générer de cassure double-brin dans la séquence cible, a été récemment proposée (Komor et al 2016). Elle permet d'envisager une correction beaucoup plus fine des variations ponctuelles associées à des pathologies humaines ou animales. Elle facilite également le multiplexage (modification simultanée de plusieurs régions), et devrait donc permettre d'évaluer plus efficacement la contribution des variants génétiques aux phénotypes cellulaires et tissulaires.

La technique CRISPR-Cas9 peut également être employée pour modifier le génome de microorganismes (bactéries, levures) utilisés pour la production industrielle de produits chimiques, pharma- ceutiques, de polymères ou de carburants à partir de biomasse, source très importante de carbone renouvelable (biotechnologies blanches; voir par exemple Estrela et Cate 2016).

Elle permet aussi l'élaboration de systèmes dits de "gene drive » (appelés aussi systèmes de " guidage » ou « forçage » génétique, ou encore d'hérédité " supermendélienne »). Ces derniers permettent de modifier très rapidement, en quelques générations seulement, un ou des gène(s) cible(s) dans des populations entières. $\mathrm{Si}$, par exemple, les gènes inactivés sont indispensables à la reproduction de l'espèce, cela peut conduire à son éradication. Ceci a été testé avec succès pour différentes espèces d'insectes vecteurs de maladies majeures chez l'Homme, dont le paludisme, responsable de plus de 500000 morts par an (Hammond et al 2016). Les mêmes approches pourraient constituer des moyens de lutte efficaces contre certaines espèces invasives, devenues résistantes à des insecticides, herbicides, anthelminthiques, par exemple (voir la revue de Champer et al 2016).

CRISPR-Cas9 peut enfin être utilisée pour modifier le génome de plantes, modèles ou cultivées (Khatodia et al 2016), ou celui d'animaux d'élevage, avec des visées biomédicales ou agronomiques. Dans le domaine biomédical, on pense à la création de nouveaux modèles animaux de pathologies humaines plus pertinents que la souris (Whitelaw et al 2015) ou à la production de greffons, en particulier porcins, pour la xénotransplantation (Niemann et Petersen 2016). Les applications agronomiques envisagées sont présentées plus en détail dans le chapitre suivant.

\section{2 / Applications agronomiques de CRISPR-Cas9 (animaux d'élevage)}

Produire des animaux génétiquement modifiés pour " nourrir l'humanité » n'est pas une idée récente (Houdebine 1998, 2005). De nombreux travaux de recherche ont été conduits dans le passé dans ce domaine (voir la revue de Fahrenkrug et al 2010). La production de certaines lignées, comme par exemple le saumon Aquadvantage ${ }^{\circledR}$, présentant une vitesse de croissance doublée par rapport au témoin sauvage (Ledford 2015b), ou le porc Enviropig $\AA$, permettant de réduire de $75 \%$ les émissions de phosphore dans les lisiers, (Golovan et al 2001), a attiré l'attention de la communauté scientifique et du grand public, et suscité certaines controverses (Clausen et Longo 2012). La commercialisation de variétés de plantes génétiquement modifiées est chose commune dans certaines régions du monde depuis le milieu des années 1990 : en 2014, 181,5 millions 
Tableau 1. Applications pour la recherche de la technique CRISPR-Cas9.

\begin{tabular}{|c|c|c|c|}
\hline \multicolumn{4}{|c|}{ Modifications par des cassures ciblées dans l'ADN } \\
\hline Fonction & Description & Applications & Références \\
\hline $\begin{array}{l}\text { Cassure ciblée } \\
\text { double-brin }\end{array}$ & $\begin{array}{l}\text { L'activité nucléase de Cas9 produit } \\
\text { des cassures double-brin au niveau } \\
\text { des séquences homologues à celle } \\
\text { de l'ARN guide }\end{array}$ & $\begin{array}{l}\text { Invalidation de gènes par NHEJ }{ }^{(1)} \\
\text { Insertion ciblée de séquence } \text { par KI }^{(2)} \\
\text { ou édition de bases par } \mathrm{RH}^{(3)} \\
\text { Multiplexage possible }\end{array}$ & $\begin{array}{l}\text { Jinek et al (2012) } \\
\text { Cong et al (2013) }\end{array}$ \\
\hline $\begin{array}{l}\text { Cassure ciblée } \\
\text { simple-brin }\end{array}$ & $\begin{array}{l}\text { Une mutation de Cas9 transforme son } \\
\text { activité nucléase en activité nickase, } \\
\text { permettant des cassures simple-brin } \\
\text { au niveau des séquences } \\
\text { homologues à celle de l'ARN guide }\end{array}$ & $\begin{array}{l}\text { Les cassures simple-brin augmentent } \\
\text { la fréquence de RH } \\
\text { La combinaison de deux cassures } \\
\text { simples par deux ARN guides } \\
\text { augmente la spécificité }\end{array}$ & $\begin{array}{l}\text { Ran et al (2013b) } \\
\text { Mali et al (2013) }\end{array}$ \\
\hline $\begin{array}{l}\text { Screening } \\
\text { fonctionnel }\end{array}$ & $\begin{array}{l}\text { Une librairie de milliers de plasmides, } \\
\text { chacun codant un ARN guide ciblant } \\
\text { un gène différent, permet d'identifier } \\
\text { les gènes importants pour le contrôle } \\
\text { d'un phénotype donné }\end{array}$ & $\begin{array}{l}\text { Identifier des gènes importants pour } \\
\text { un phénotype donné, en réponse à un } \\
\text { stress, une infection, etc }\end{array}$ & $\begin{array}{l}\text { Chen et al (2015) } \\
\text { Wang et al (2015) } \\
\text { Shalem et al (2015) }\end{array}$ \\
\hline \multicolumn{4}{|c|}{ Modifications ciblées sans cassure au niveau de l'ADN } \\
\hline Fonction & Description & Applications & Références \\
\hline $\begin{array}{l}\text { Réprimer ou } \\
\text { activer la } \\
\text { transcription }\end{array}$ & $\begin{array}{l}\text { Utilisation d'une Cas9 mutée }{ }^{(4)} \text { mais } \\
\text { se fixant sur l'ADN au niveau de la } \\
\text { séquence cible } \\
\text { Cas9 peut également être fusionnée } \\
\text { avec des protéines inhibant ou } \\
\text { activant la transcription }\end{array}$ & $\begin{array}{l}\text { Occupation spatiale de sites de } \\
\text { fixations pour des facteurs régulant la } \\
\text { transcription. } \\
\text { Activation ou inhibition ciblée de la } \\
\text { transcription }\end{array}$ & $\begin{array}{l}\text { Gilbert et al (2014) } \\
\text { Gilbert et al (2013) } \\
\text { Kearns et al (2014) } \\
\text { Konermann et al (2015) }\end{array}$ \\
\hline $\begin{array}{l}\text { Editer sans } \\
\text { casser }\end{array}$ & $\begin{array}{l}\text { Une Cas } 9 \text { mutée est fusionnée avec } \\
\text { une enzyme qui déamine les cytidines } \\
\text { Les cytidines à proximité de la } \\
\text { séquence homologue de l'ARN guide } \\
\text { sont transformées en uridine }\end{array}$ & $\begin{array}{l}\text { Base editing: substitution C vers } \mathrm{T} \\
\text { (ou G vers A) } \\
\text { L'efficacité est cependant fonction du } \\
\text { contexte }\end{array}$ & Komor et al (2016) \\
\hline $\begin{array}{l}\text { Méthyler ou } \\
\text { déméthyler } \\
\text { l'ADN }\end{array}$ & $\begin{array}{l}\text { Une Cas9 mutée est fusionnée avec } \\
\text { une méthyltransférase de l'ADN } \\
\text { (méthylation) ou une enzyme TET } \\
\text { (déméthylation) } \\
\text { La méthylation des CpG autour de la } \\
\text { séquence homologue de l'ARN guide } \\
\text { est modifiée en relation avec } \\
\text { l'enzyme utilisée }\end{array}$ & $\begin{array}{l}\text { Méthylation ou déméthylation ciblée } \\
\text { de l'ADN } \\
\text { Activation ou répression de } \\
\text { promoteurs, modification d'épi-allèles, } \\
\text { etc }\end{array}$ & $\begin{array}{l}\text { Amabile et al (2016) } \\
\text { Liu et al (2016) }\end{array}$ \\
\hline $\begin{array}{l}\text { Visualiser des } \\
\text { régions } \\
\text { génomiques }\end{array}$ & $\begin{array}{l}\text { Une Cas9 mutée est fusionnée avec } \\
\text { une protéine fluorescente } \\
\text { Les séquences homologues du ou } \\
\text { des ARN guides sont visualisables en } \\
\text { microscopie à fluorescence }\end{array}$ & $\begin{array}{l}\text { Visualisation dans des cellules } \\
\text { vivantes de régions génomiques } \\
\text { ciblées. } \\
\text { Visualisation de régions d'ADN en } \\
\text { interactions }\end{array}$ & $\begin{array}{l}\text { Chen et al (2013) } \\
\text { Ma et al (2015) } \\
\text { Nelles et al (2016) } \\
\text { Ochai et al (2015) }\end{array}$ \\
\hline $\begin{array}{l}\text { Isoler un } \\
\text { complexe } \\
\text { contenant une } \\
\text { séquence } \\
\text { d'ADN cible }\end{array}$ & $\begin{array}{l}\text { Une Cas9 mutée est fusionnée avec } \\
\text { un épitope immunogène } \\
\text { Les complexes contenant la } \\
\text { séquence homologue du ou des ARN } \\
\text { guide peuvent être purifiés par } \\
\text { immuno-affinité }\end{array}$ & $\begin{array}{l}\text { Etudier des interactions } \\
\text { ADN/Protéines, ADN/ADN ou } \\
\text { ADN/ARN, etc }\end{array}$ & Fujita et Fujii (2013) \\
\hline
\end{tabular}

(1) NHEJ : Non Homologous End Joining, ou ligation non-homologue des extrémités; ${ }^{(2)} \mathrm{KI}$ : knock-in, ou modification "gain de fonction "; ${ }^{(3)} \mathrm{RH}$ : recombinaison homologue ; ${ }^{(4)}$ : Cas9 mutée : protéine dont la fonction de clivage de l'ADN a été inactivée.

d'hectares, soit $13 \%$ des terres arables à l'échelle mondiale étaient cultivés par 18 millions d'agriculteurs de 28 pays avec des plantes génétiquement modifiées (Lucht 2015). La situation est très différente pour les espèces animales. Le saumon Aquadvantage ${ }^{\circledR}$ est actuellement la seule lignée transgénique à bénéficier d'une autorisation de commercialisation, délivrée fin 2015 par l'administration américaine, après 20 ans de procédures (Ledford 2015b).
Les raisons expliquant ce fort contraste entre plantes et animaux sont nombreuses. Certaines sont liées à des questions d'acceptabilité de ce type de produits par les consommateurs. D'autres sont d'ordre scientifique et/ou technique : jusqu'à une période récente, les méthodes disponibles dans le règne animal étaient insuffisamment précises, ne permettant pas de maîtriser avec suffisamment de garantie l'ensemble des effets liés aux modifications induites, et/ou trop complexes à mettre en œuvre. Peu d'applications pertinentes étaient à un stade de développement suffisamment avancé pour justifier le passage à une échelle commerciale. D'autres explications, enfin, sont d'ordre économique : coût très élevé du développement et de l'entretien de lignées d'animaux génétiquement modifiés, en raison, notamment, de la faible efficacité des techniques disponibles, expliquant la finalité « biomédicale » de beaucoup de projets 
entrepris jusqu'alors. Cependant, les avancées spectaculaires en termes de connaissance des génomes (voir par exemple Daetwiller et al 2014), et la rupture technologique que représente CRISPR-Cas9, ont induit une explosion des travaux d'ingénierie des génomes animaux au cours des dernières années (Tan et al 2016). Ceci, accompagné d'une forte mobilisation de certains leaders d'opinion, est probablement de nature à faire évoluer la situation au cours des années à venir : voir par exemple l'éditorial du $\mathrm{N}^{\circ} 48$ (103) de Nature Genetics paru le 27 janvier 2016, la lettre à l'éditeur de Nature Biotechnology (Caroll et al 2016), ou 1'opinion de Murray et Maga (2016), publiée dans un récent numéro de PNAS (29 mars 2016). La multiplication des congrès, colloques et workshops, sur ce thème ${ }^{2,3}$, ou la lettre signée par 109 lauréats du Prix Nobel à la direction de Greenpeace ${ }^{4}$, enjoignant ces derniers à mettre un terme à leurs campagnes d'opposition aux OGM, les assimilant à un « crime contre l'humanité » (sic), témoignent aussi de la volonté d'une partie du monde scientifique de profiter de l'avènement des nouvelles techniques (NBT : "New Breeding Techniques ») pour s'engager plus résolument dans le développement d'organismes génétiquement modifiés, y compris animaux.

Il serait impossible de citer ici l'ensemble des travaux entrepris à ce jour. Une liste des modifications réalisées dans les espèces bovine, ovine, caprine et porcine à l'aide des nucléases programmables ZFN, TALEN et CRISPR-Cas9, et publiées avant fin 2015, a été établie par Tan et al (2016). Une synthèse des réalisations et des perspectives concernant les espèces aviaires a été récemment proposée par Doran et al (2016). L'ensemble des applications envisagées pour les espèces animales est également bien résumé et mis en perspective dans le texte de Reardon (2016) : « The CRISPR zoo ». Nous n'évoquerons de façon détaillée dans la suite de ce texte que quelques travaux illustrant bien certains types d'applications régulièrement mises en avant par les promoteurs de ces technologies, parce que plus faciles à justifier auprès de la société que d'autres, ou répondant à certaines critiques classiquement adressées par une partie de la société au secteur de l'élevage (Delanoue et Roguet 2015) : i) les modifications ciblées du génome visant à améliorer la santé des animaux d'élevage, qu'on ne peut dissocier de celle de l'Homme (concept «One Health», Zinsstag et al 2011), ii) celles permettant de ne plus recourir à des pratiques d'élevage très mal perçues car altérant le bien-être des animaux, et iii) celles visant à modifier les caractéristiques des produits animaux (lait, œufs, viande) dans une perspective d'amélioration de la nutrition et de la santé de l'Homme. Une application potentiellement intéressante chez des poissons d'élevage sera également évoquée en fin de chapitre.

\section{a) Modifications ciblées du génome visant à améliorer la santé des animaux d'élevage}

La gestion des problèmes de santé en élevage est un sujet complexe. Un consensus assez large existe néanmoins pour considérer que les approches les plus efficaces et durables sont celles mobilisant de façon complémentaire différents leviers d'action : amélioration des conditions d'élevage (logement, alimentation, protections sanitaires...), utilisation raisonnée des vaccins et des médicaments pour éviter l'apparition trop rapide de résistances, et sélection d'animaux présentant une robustesse naturelle face aux maladies (enjeux du métaprogramme INRA GISA, Gestion Intégrée de la Santé des Animaux, http://www.gisa.inra.fr).

Les méthodes de sélection fondées sur l'exploitation de la variabilité génétique existant au sein des populations, incluant donc la sélection assistée par marqueurs ou la sélection génomique, ont d'ores et déjà permis d'obtenir des résultats très probants en matière de résistance génétique à certaines pathologies infectieuses d'importance économique majeure en élevage : mammites chez les ruminants laitiers (Sender et al 2013, Riggio et Portolano 2015), tremblante ovine, helminthoses et autres maladies infectieuses chez les petits ruminants (Elsen et al 1999, Bishop 2015), par exemple. Mais les méthodes d'ingénierie ciblée des génomes, complémentaires, ouvrent d'autres perspectives qui doivent être considérées. Quelques exemples sont développés ci-dessous.

Chez les bovins, une équipe chinoise a récemment produit, en modifiant des fibroblastes fotaux en culture à l'aide de la technologie ZFN, puis par clonage SCNT, cinq animaux transgéniques produisant dans leur glande mammaire le lysozyme et la lactoferrine humaines, deux protéines disposant de propriétés antimicrobiennes et sécrétées naturellement dans la salive ou le lait (Liu et al 2014). Suite à l'inoculation intra-mammaire expérimentale de germes pathogènes (Staphylococcus aureus, Streptococcus agalactiae et Escherichia coli), ces animaux, contrairement aux témoins, n'ont présenté aucune infection (bactériémies négatives), ni aucun signe clinique, démontrant la validité du concept (stratégie potentiellement efficace de lutte contre les mammites).

Le syndrome dysgénésique et respiratoire porcin (SDRP, ou PRRS en anglais) est la maladie ayant les répercussions économiques les plus importantes en élevage porcin à l'échelle mondiale. Aux USA, où sévissent les souches virales les plus pathogènes (génotype 2, que l'on trouve aussi en Asie), le coût annuel est estimé à plus de $600 \mathrm{M} \$$ (Whitworth et al 2014). Le contrôle de cette maladie se révèle très difficile, en raison de l'extrême variabilité du virus. Les souches vaccinales sont généralement différentes des souches sévissant dans les élevages, limitant l'efficacité des vaccins. Les études physiopathologiques réalisées il y a quelques années ont montré un tropisme très étroit du virus PRRSV pour les macrophages, une des portes d'entrée du PRRSV dans la cellule étant la protéine CD163 (Van Breedam et al 2010). L'invalidation du gène codant cette protéine chez des animaux expérimentaux a été entreprise par un groupe de chercheurs de l'Université du Missouri, financé en partie par l'entreprise Genus, leader mondial de la sélection porcine. Des zygotes produits par fécondation in vitro ont pour cela subi une micro-injection (ARN messager de Cas9 et sgRNA), induisant la modification d'un ou des deux allèles du gène ciblé dans $100 \%$ des blastocystes étudiés (Whitworth et al 2014). Après transfert des embryons modifiés, plusieurs porcelets ayant leurs deux copies inactivées (notés CD163-/-), homozygotes ou hétérozygotes composites, ont été obtenus. Trois d'entre eux, accompagnés de 8 témoins, ont été transférés dans des installations ad hoc de la "Kansas State University », soumis à une infection expérimentale, et suivis cliniquement pendant 35 jours. Tous les animaux témoins ont présenté des signes cliniques caractéristiques de la maladie (avec un pic entre J5 et J14). À l'inverse, et en dépit d'une exposition permanente due à la cohabitation avec les témoins, les 3 animaux CD163 -/ont conservé une virémie nulle sur l'ensemble de la période. Ces animaux n'ont par ailleurs montré aucune réponse anticorps ni aucun signe clinique (Whitworth et al 2016). Pour pallier d'éventuels troubles physiologiques et/ou de santé liés à la perte totale par l'organisme de la protéine CD163, des chercheurs du Roslin Institute à Edinburgh

\footnotetext{
2 http://lage.usu.edu

http://www.nib.ac.uk/event/genome-editing-and-the-future-of-farming/

${ }^{4}$ http://supportprecisionagriculture.org/nobel-laureate-gmo-letter rjr.html
} 
ont récemment produit de nouveaux porcelets dont la protéine a été simplement amputée de son domaine SRCR5 permettant l'interaction avec le virus (par délétion de l'exon 7 du gène ; Burkard et al 2017). Ces porcelets, suivis pendant plusieurs mois, présentaient des vitesses de croissance et des paramètres sanguins normaux. Des tests in vitro ont par ailleurs montré une activité biologique normale de la protéine CD163 modifiée, et une résistance complète des macrophages à l'infection par des virus de différents génotypes. Ces différentes études, relativement convaincantes, n'évaluaient toutefois pas si le PRRSV peut utiliser d'autres voies d'entrée dans les macrophages pulmonaires, comme le suggère une publication récente (Doeschl-Wilson et al 2016).

D'autres maladies d'origine virale ont un fort potentiel zoonotique. C'est le cas en particulier de l'influenza aviaire, maladie pour laquelle le contrôle vaccinal (interdit chez les volailles en France), ou par des méthodes de biosécurité, est également difficile. Rendre les animaux résistants à ce type de virus, en recourant éventuellement à des méthodes d'ingénierie génétique, est donc potentiellement intéressant pour l'économie des filières agricoles concernées, mais également en termes de santé publique. C'est avec cet objectif que Lyall et al (2011), de l'Université de Cambridge, en association avec le Roslin Institute, Université d'Edinburgh, ont imaginé un système de résistance au virus fondé sur l'interférence à ARN. L'idée générale de leurs travaux consistait à intégrer dans le génome de poulets, à l'aide de vecteurs lentiviraux, des transgènes exprimant une courte séquence d'ARN en épingle à cheveux (shRNA, short-hairpin $R N A)$. Cet ARN, transcrit par les cellules des animaux transgéniques, était conçu pour fonctionner comme un leurre, attirant et bloquant la polymérase du virus, perturbant donc la réplication de ce dernier. Dans ces travaux fondateurs, publiés en 2011, tous les animaux transgéniques infectés expérimentalement par une souche virale hautement pathogène ont succombé à l'infection. Cependant, la transmission du virus à d'autres animaux, transgéniques ou non, élevés en contact étroit avec les animaux infectés, a pu être évitée. Ce résultat montre la pertinence de ce type d'approche pour contrôler la propagation de la maladie au sein d'élevages ou de territoires. Les animaux transgéniques de Lyall et al (2011) ont été produits à l'aide de méthodes de transgénèse antérieures à CRISPR-Cas9 (transduction du shRNA à l'aide d'un vecteur lentiviral dans des embryons d'œufs fraichement pondus). Un jeune coq produisant le transgène dans sa semence a été utilisé pour procréer des descendants ayant intégré la même copie unique du transgène sur leur chromosome 2. D'autres travaux du même type pourraient être réalisés avec une précision et une efficacité accrue en mobilisant les techniques les plus récentes de modifications ciblées (CRISPR-Cas9).

\section{b) Modifications ciblées du génome permettant de ne plus recourir à certaines pratiques d'élevage}

Certaines pratiques d'élevage (castration, gavage, écornage, élimination de poussins...) font l'objet de campagnes de dénonciations virulentes organisées par certaines associations défendant la cause animale (L214 notamment). Une conséquence de ces campagnes est que le souhait d'abandonner ces pratiques est de plus en plus partagé au sein de la société. Leur abandon peut passer par une évolution des systèmes et des pratiques d'élevage, et/ou par une réorganisation des filières (alternatives au gavage : voir par exemple Guy et al 2013 ; alternatives à la castration chirurgicale des porcelets : voir par exemple von Borell et al 2009). Cependant, dans ce domaine également, l'ingénierie ciblée des génomes peut être une option a priori séduisante. Deux exemples sont développés ci-dessous.

L'écornage des animaux est une pratique utilisée depuis fort longtemps en élevage bovin. Les cornes sont nécessaires aux bovidés sauvages pour s'alimenter (débroussaillage) et se défendre contre les prédateurs. Mais, dans le contexte actuel de l'élevage, avec un usage très répandu de la stabulation libre, elles présentent de nombreux inconvénients qui, pour beaucoup d'éleveurs, justifient leur élimination : accès plus difficile aux cornadis, à la salle de traite ou aux robots, danger pour les congénères, pour les éleveurs, les vétérinaires, les inséminateurs, risque d'endommagement des équipements d'élevage, etc. Cette élimination peut être réalisée à l'âge adulte, ou, plus habituellement, durant le jeune âge, par brûlage. Pour des raisons pratiques et économiques, aucune anesthésie ni analgésie n’est généralement réalisée. Cette dernière est toutefois obligatoire pour les veaux de plus de 4 semaines. Ce type d'intervention est pratiqué chaque année sur des millions de veaux : plus de 10 millions pour les seuls USA (Carlson et al 2016), ce qui pose clairement question dans une perspective de promotion du bien être animal en élevage. Une alternative à l'écornage est l'élevage d'animaux nés sans corne. Cette possibilité est considérée avec un regain d'intérêt depuis la récente découverte de la nature moléculaire du gène « sans corne » (Medugorac et al 2012) et le développement de tests de génotypage. Deux allèles « sans corne », de structure molécu- laire assez différente, ont été caractérisés. L'un, d'origine celtique $\left(\mathrm{P}_{\mathrm{C}}\right)$, est en ségrégation dans différentes races françaises (Charolaise, Limousine, Blonde d'Aquitaine, Aubrac...) et européennes. L'autre, d'origine frisonne $\left(\mathrm{P}_{\mathrm{F}}\right)$, se retrouve en race Holstein. Ces deux allèles ont un effet dominant (par rapport à l'allèle " cornu »). Plusieurs entreprises de sélection disposent aujourd'hui d'une offre de taureaux sans cornes. Une option pour les éleveurs qui souhaitent accroitre la fréquence d'animaux sans corne au sein de leurs troupeaux consiste donc à utiliser des taureaux « sans corne » et à conserver les descendants ayant hérité de cet allèle. Cette stratégie présente toutefois deux inconvénients : $i$ ) le temps nécessaire à l'augmentation de la fréquence de l'allèle " sans corne » au sein des populations; si on considère les vaches de race Holstein aux USA, par exemple, on constate que le nombre d'individus sans corne a été multipliée par 10 au cours des 10 dernières années ; à ce rythme-là, il faudrait encore 20 ans pour que la fréquence des individus sans corne atteigne 50\% (Dorshorst 2014, cité par Carlson et al 2016) ; ii) dans des races comme la Holstein, le niveau génétique sensiblement plus faible des taureaux porteurs du gène " sans corne » actuellement disponibles (pour les caractères de l'objectif de sélection), en raison, probablement, du niveau génétique moyen des fondateurs chez lesquels le gène « sans corne » a été initialement introgressé.

Une alternative consisterait à introduire directement le gène "sans corne » dans des cellules en culture d'actuels taureaux d'élite pour produire, par SCNT, des clones de ces individus, homozygotes pour le gène sans corne, dont toute la descendance serait par conséquent sans corne. Cette stratégie «d'introgression non méiotique » de gène(s) d'intérêt a été mise en œuvre à l'Université du Minnessota (Tan et al 2013). L'allèle $\mathrm{P}_{\mathrm{C}}$ a été introduit dans les fibroblastes en culture d'un individu « cornu » de race Holstein en utilisant la technique TALEN-HDR. Cet allèle $P_{C}$ correspond à une insertion-délétion complexe sur le chromosome 1 (duplication de $212 \mathrm{pb}$ qui remplace un segment de $10 \mathrm{pb}$ ). Sur un total de 226 colonies cellulaires analysées, 5 (soit $2 \%$ ) portaient la modification souhaitée, dont 3 sur les deux copies du gène. Le séquençage réalisé a permis de vérifier l'absence de modification « hors cible ». Des cellules homozygotes, porteuses de deux copies modifiées, ont été utilisées pour produire des veaux par SCNT. Cinq sont nés vivants, et deux (Spotigy et Bury) étaient en parfaite santé à l'âge de 10 mois. Ils sont toujours en cours d'évaluation à l'Université de Californie, Davis (Carlson et al 2016). 
Une autre pratique, ayant fait l'objet d'une campagne de dénonciation importante au cours des derniers mois, est l'élimination systématique, lors de l'éclosion, et à l'aide de méthodes parfois non appropriées, de poussins d'un sexe donné, par exemple des mâles dans le cas de la production de poussins femelles destinés à la ponte. Ces poussins mâles, issus de souches sélectionnées pour les aptitudes de ponte, sont en effet non adaptés à la production de poulets de chair, en raison d'une croissance, d'une composition corporelle et de comportements inadaptés aux exigences des filières. Pour éviter cette destruction massive de poussins, l'équipe de Tim Doran et Mark Tizard en Australie (CSIRO) a imaginé un système de production original valorisant la transgénèse. Ce système est décrit à la figure 3. Il consiste à produire une lignée d'individus transgéniques dont le chromosome $\mathrm{Z}$, noté $\mathrm{Z}^{\mathrm{GFP}}$ a intégré un transgène codant une protéine fluorescente (GFP). Chez les oiseaux, c'est le sexe femelle qui est hétérogamétique (ZW), les mâles disposant dans chacune de leurs cellules de deux chromosomes Z. Les femelles de la lignée transgénique (individus $\mathrm{Z}^{\mathrm{GFP} W}$ ) sont inséminées par de la semence de coqs d'autres lignées sélectionnées non transgéniques (individus ZZ). Les produits de ces accouplements sont des femelles ZW (qui ont hérité d'un chromosome $\mathrm{W}$ non génétiquement modifié de leur mère transgénique, et d'un chromosome $Z$ de leur père non transgénique), et des mâles $Z^{\mathrm{GFP} Z}$, dont l'un des chromosomes $Z$, celui hérité de leur mère, porte le gène codant la GFP.
Seules les femelles ayant un intérêt pour la filière «ponte », les mâles doivent être écartés. Ceux-ci peuvent l'être par un mirage des œufs réalisé précocement au cours de la phase d'incubation (détection de la fluorescence). Les œufs présentant un signal de fluorescence sont alors orientés vers un autre circuit de valorisation (industrie pharmaceutique, chimie...) bien avant l'éclosion, tandis que les autres sont gardés en incubation pour la production de poussins femelles (ZW) destinés à devenir des poules pondeuses. Ces femelles sont issues d'un parent transgénique, mais ne portent pas elles-mêmes de transgène, ce qui pose la question de leur statut : les promoteurs de ce dispositif considèrent que ces animaux ne sont pas génétiquement modifiés et qu'ils devraient par conséquent échapper à toute réglementation « OGM ». Ce dispositif, séduisant à certains égards, reste pour l'instant, à notre connaissance, à l'état de projet (pas de publication parue). Quelques inconnues restent par ailleurs à lever. Par exemple, quel promoteur utiliser pour obtenir une intensité optimale de fluorescence détectable dans les œufs? On peut toutefois penser qu'avec les techniques actuelles de transgénèse, il pourrait devenir réalité à assez court terme. Se posera alors la question de l'acceptabilité par le consommateur de ce type d'approche.

c) Modifications ciblées du génome visant à améliorer la nutrition et la santé de l'Homme

Parmi les nombreuses questions que l'Homme se pose actuellement concer-

Figure 3. Dispositif imaginé par l'équipe de Mark Tizard et Tim Doran (CSIRO, Australie) permettant de trier les œufs contenant les embryons mâles avant éclosion (production de poussins femelles destinées à la ponte) (d'après Mark Tizard, CSIRO : http://www.isb.vt.edu/documents/animal-biotech/2nd-Intl-Workshop-docs/Day1/Tizard\%20-\%20PGE\%20in\%20chicken.pdf).

Ce dispositif valorise une lignée transgénique (femelles portant un gène codant une protéine fluorescente sur le chromosome sexuel Z).

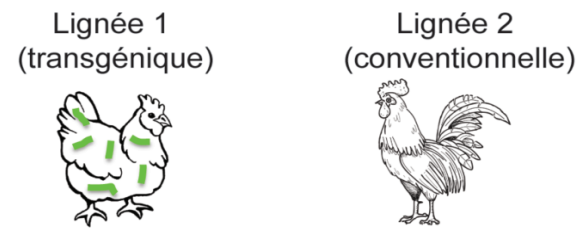

Femelles ZGFPW

Mâles ZZ
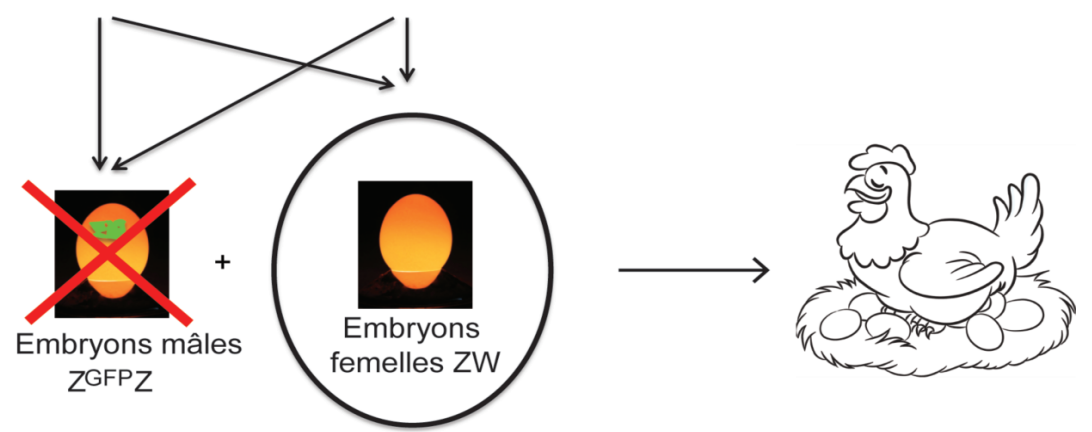

nant son alimentation, celle des allergies alimentaires fait partie des plus importantes. Les allergies au lait de vache (Lifschitz et Szajewska 2015) ou à l'œuf (Caubet et Wang 2011) comptent parmi les plus fréquentes chez le jeune enfant, et sont difficiles à gérer pour les individus concernés dans la mesure où ces produits sont utilisés pour l'élaboration de très nombreuses préparations alimentaires ou non-alimentaires (protéines d'œuf présentes dans certains vaccins par exemple). L'élimination de ces aliments, sans substitution appropriée, peut par ailleurs être à l'origine de carences ou de malnutrition très préjudiciables durant la croissance de l'enfant. Les principales molécules allergisantes sont des protéines : caséines, lactalbumine, lactoglobuline pour le lait, ovalbumine, ovomucoïde pour le blanc d'œuf. Ces protéines, comme toutes les autres, sont le produit de gènes particuliers. L'inactivation de ces gènes chez les animaux pourrait donc être envisagée, dans des filières d'élevage spécialisées, pour la production d'aliments adaptés aux régimes de personnes allergiques, ou, plus globalement, pour atténuer la fréquence de ces allergies chez l'enfant.

C'est dans cette perspective qu'une équipe chinoise a entrepris, dès 2011, une première série de travaux visant à procréer des bovins $\mathrm{KO}$ pour le gène de la $\beta$-lactoglobuline $(B L G$; Yu et al 2011). Des fibroblastes fœtaux en culture ont été modifiés à l'aide de la technologie ZFN, ciblant $B L G$. Des colonies cellulaires présentant des modifications sur les deux copies du gène ont été utilisées pour produire des veaux KO par clonage SCNT. Parmi les 8 veaux nés (tous confirmés homozygotes mutés par séquençage), 6 sont morts prématurément avec des troubles cliniques caractéristiques des animaux issus de SCNT, soulignant la principale limite de cette approche. Les deux survivants, qui étaient âgés de 6 mois lors de la parution de la publication, ne présentaient pas de problème de santé particulier. D'autres travaux du même type ont été réalisés ultérieurement chez le bovin (Wei et al 2015) ainsi que chez la chèvre (Xiong et al 2013, Song et al 2015).

Des travaux comparables ont également été réalisés chez le poulet par l'équipe coréenne de TS Park (Park et al 2014), la première à utiliser les nucléases programmables dans cette espèce. La technologie TALEN a été employée pour générer une cassure dans l'exon $2 \mathrm{du}$ gène codant l'ovalbumine au sein de PGC en culture. Des délétions de 6 à 29 nucléotides, inactivant le gène, ont été constatées dans $33 \%$ des cellules analysées. Ces cellules ont été réinjectées dans des embryons 
de poulets pour donner naissance à des individus chimériques. Ces derniers ont été accouplés à des individus non modifiés pour procréer plusieurs descendants G1 portant une copie du gène muté dans chacune de leurs cellules. Aucune anomalie n'a été détectée chez ces animaux. Le séquençage de leur génome n'a révélé aucune modification hors cible. Le même type de travaux a été entrepris plus récemment par une équipe japonaise, mais, cette fois, et pour la première fois chez le poulet, à l'aide de la technologie CRISPR-Cas9 (Oishi et al 2016). Deux gènes étaient ciblés dans ces travaux (ovalbumine et ovomucoide), qui sont allés jusqu'à l'obtention d'individus G2 mutés sur les deux copies du gène de l'ovomucoide. Les résultats obtenus démontrent une nouvelle fois la grande efficacité et la précision de cette technique : taux de transformation cellulaire supérieur à $90 \%$, pas de modification hors-cible détectée dans les trois régions candidates analysées. L'impact à long terme de l'absence d'une protéine aussi importante que l'ovalbumine pour le développement et la croissance embryonnaire devrait toutefois être évalué avant d'envisager une application commerciale de ce genre de travaux.

Tous les exemples développés plus haut concernent des espèces d'élevage terrestres. Mais la technique CRISPRCas9 a également été utilisée avec succès chez différentes espèces de poissons. Des résultats probants ont été obtenus pour le poisson-zèbre (zebrafish, Danio rerio), espèce modèle, dès 2013 (Hwang et al 2013), rapidement suivis d'autres résultats chez des espèces d'élevage : saumon (Edvardsen et al 2014), tilapia (Li et al 2014) ou carpe (Chakrapani et al 2016), par exemple. L'élevage en cages offshore d'espèces marines, telles que le saumon atlantique (Salmo salar), induit un risque d'échappement d'individus d'élevage dans le milieu naturel, source potentielle de pollution génétique des populations sauvages. Pour se prémunir d'un tel risque, des mesures physiques de confinement sont prises, mais leur efficacité n'est pas absolue. Une mesure complémentaire de protection, utilisée à grande échelle, consiste en l'élevage d'individus femelles triploïdes stériles (Benfey 2016). Cette stratégie a cependant ses propres limites. Les principales sont la fréquence accrue d'anomalies morphologiques et de cataracte chez ces individus triploïdes, leur moindre résistance aux pathologies infectieuses et parasitaires, et leur moindre tolérance à l'élévation de température (Benfey 2016). La triploïdisation, également utilisée pour la production d'huîtres, est par ailleurs assez mal acceptée par les consommateurs. Une autre stratégie permettant l'obtention d'individus stéri- les, avec la technique CRISPR-Cas9, a récemment été proposée et validée expérimentalement par Wargelius et al (2016) chez le saumon. Elle consiste, par micro-injection dans des zygotes d'un sgRNA et d'ARN messager de Cas9, à inactiver les deux copies du gène $d n d$. Chez les vertébrés, la protéine Dnd se lie à l'extrémité 3'UTR des ARN spécifiques des cellules germinales, les protégeant d'une inhibition par les micro-ARN et leur permettant de maintenir cet état de cellules germinales primordiales. L'inactivation de ce gène conduit, chez le saumon, à des individus mâles ou femelles phénotypiquement normaux, dont les gonades ne contiennent aucune cellule germinale. Ces animaux sont donc stériles, sans autre effet associé. Compte tenu de l'efficacité élevée de la technique CRISPR-Cas9, cette méthode d'obtention d'individus stériles pourrait devenir une alternative intéressante à la production d'animaux triploïdes.

\section{3 / Questions posées par les techniques de modifications ciblées des génomes}

Les quelques exemples développés dans la partie précédente illustrent l'efficacité et le potentiel des nucléases programmables, et de CRISPR-Cas9 en particulier, pour la production de nouvelles lignées d'animaux génétiquement modifiés. Ces méthodes représentent, dans le domaine de l'ingénierie génétique, une réelle rupture technologique. Des raffinements méthodologiques visant à améliorer la précision, le potentiel de multiplexage, ou l'innocuité des méthodes, par exemple, doivent encore être apportés. Toutefois, des efforts de recherche très importants sont actuellement en cours (voir la revue de Komor et al 2017). Des investisseurs très réputés sont entrés au capital des principales start-up du domaine : Editas Medicine, Intellia Therapeutics, Caribou Bioscience, CRISPR Therapeutics etc. Des moyens financiers considérables accompagnent donc ces efforts de recherche, ce qui permet de penser que les améliorations techniques nécessaires seront opérationnelles rapidement.

Le déploiement de ces méthodes pour l'obtention d'animaux génétiquement modifiés dépendra étroitement de l'évolution des connaissances en matière de déterminisme et de variabilité génétique des caractères d'intérêt. Dans ce domaine, deux points de vue assez symétriques peuvent être défendus. Le premier consiste à considérer que de nombreux gènes majeurs (polymorphismes expliquant une part importante de la variabilité génétique d'un ou de plu- sieurs caractères importants en sélection) ont été identifiés dans le passé dans les espèces d'élevage : gènes d'hypertrophie musculaire chez les bovins (Grobet et al 1997) ou les ovins (Cockett et al 2005), gènes d'hyperovulation chez la brebis ou la vache (Vinet et al 2012), gènes d'adaptation à la chaleur chez le poulet (Mou et al 2011), gènes affectant de façon importante la composition en matières utiles du lait de vache (Grisart et al 2002), la prédisposition aux mammites chez la brebis (Rupp et al 2015) ou la qualité de la viande de porc (Milan et al 2000) etc. Une partie de ces gènes pourraient d'ores et déjà être candidats à des modifications ciblées, pour introduire certains allèles dans des populations particulières, en supprimer ou en corriger d'autres. Ce pourrait aussi être le cas de nombreuses autres régions du génome où des variants responsables d'affections héréditaires sont identifiés (Nicholas et Hobbs 2014, Duchesne et al 2017). Les progrès très importants des connaissances permis par l'évolution spectaculaire des techniques d'analyse des génomes (Goodwin et al 2016) peuvent laisser penser que de nouvelles régions candidates à modification(s) par CRISPR-Cas9 pourraient être identifiées très régulièrement. Le second point de vue considère que les caractères quantitatifs sélectionnés sont essentiellement polygéniques. Les analyses d'associations pangénomiques réalisées jusqu'à présent montrent que, sauf exception, les polymorphismes contribuant le plus à la variation des caractères (QTL) n'expliquent qu'une faible part de cette variation (Kemper et Goddard 2012). Par conséquent, si quelques régions du génome peuvent effectivement faire l'objet de modifications ciblées, l'essentiel des progrès génétiques à venir devrait être le résultat des programmes actuels de sélection, avec ou sans information génomique. Une synthèse de ces deux points de vue a été proposée par Jenko et al (2015), montrant, à l'aide de simulations, les gains d'efficacité apportés à la sélection génomique par la réalisation de modifications ciblées (stratégie PAGE : «promotion of alleles by genome editing »).

L'utilisation de CRISPR-Cas9 dans les populations d'élevage pose par ailleurs différentes questions dont les sélectionneurs devront s'emparer. La durabilité des améliorations produites en est une, tout particulièrement dans le cas des modifications visant à induire une résistance de l'hôte vis-à-vis d'agents pathogènes. La dynamique évolutive de ces derniers peut être à l'origine de contournements de résistance rapides, rendant potentiellement peu pertinent et relativement vain, voire dangereux, tout effort de lutte basé sur la modification 
d'un ou de quelques gènes de l'hôte seulement. Des contournements de résistance ont été régulièrement décrits dans le cas des plantes génétiquement modifiées (résistance de populations d'insectes ravageurs aux toxines sécrétées par les variétés de maïs $B t$ notamment ; voir par exemple Tabashnik et al 2013). Les mêmes difficultés pourraient concerner certaines applications envisagées chez l'animal.

La politique à adopter par les organisations raciales 5 vis à vis des NBT est un autre aspect qu'il sera important de considérer. On peut imaginer, dans ce domaine, différents positionnements. Dans certaines populations, celles sur lesquelles s'adossent certains signes officiels de qualité par exemple, on pourrait envisager l'interdiction de toute intervention : un « variant CRISPR » particulier pourrait être formellement exclu de certains cahiers des charges. À l'inverse, on peut aussi envisager que certains sélectionneurs s'engagent dans la différentiation de nouvelles populations (races) sur la base de " variants CRISPR » originaux. La question de la brevetabilité de tels animaux pourrait par ailleurs se poser : la modification d'une seule (ou de quelques) régions du génome seraitelle suffisante pour qu'une entreprise s'approprie une génétique façonnée au cours du temps par des générations d'éleveurs?

Les modifications ciblées des génomes sont aussi susceptibles de poser des questions spécifiques en matière de gestion de la diversité génétique des populations : certains reproducteurs disposant de caractéristiques intéressantes induites par ingénierie ciblée pourraient en effet être utilisés massivement, créant de nouveaux goulets d'étranglement au sein des populations. De même, la gestion des programmes de sélection génomique pourrait être affectée par la nécessité d'estimer et de prendre en compte l'effet des nouveaux "variants CRISPR » dans les équations de prédiction génomique.

L'utilisation de ces nouvelles techniques fait également émerger d'autres types de questionnements, plus généraux, auxquels il sera parfois difficile de répondre.

Un premier type de questionnement concerne la nature juridique de ces innovations. Des arsenaux réglementaires ont été bâtis dans la plupart des pays, depuis la fin des années 1990, pour encadrer la question des organismes génétiquement modifiés (OGM) : directi- ves européennes (par exemple la directive 2001/18/CE, modifiée par la directive 2015/412/UE, donnant la possibilité aux états membres de restreindre ou d'interdire la culture d'OGM sur leur territoire), transcrites en lois nationales (par exemple la loi française $n^{\circ} 2008-595$ du 25 juin 2008 , créant le Haut Conseil aux Biotechnologies) accompagnées de leurs décrets d'application. La définition légale d'un OGM figure dans la directive 2001/18/CE : « un OGM est un organisme, à l'exception des êtres humains, dont le matériel génétique a été modifié d'une manière qui ne s'effectue pas naturellement par multiplication et/ou par recombinaison naturelle ». Jusqu'à présent, et sur la base de cette définition, c'était la méthode d'obtention qui déterminait la nécessité ou non d'une évaluation préalable à une éventuelle autorisation. Quelques techniques seulement, comme la mutagenèse, étaient exclues du champ d'application de la directive. Désormais, avec le déploiement des nucléases programmables, qui facilitent la réalisation de modifications ciblées qui, pour certaines, miment des processus cellulaires s'effectuant naturellement, les cartes sont susceptibles d'être rebattues. Un lobbying important est organisé actuellement, visant à faire évoluer la réglementation dans le sens d'une évaluation des produits eux-mêmes, sur la base de leurs caractéristiques propres, et non plus sur la seule base des méthodes ayant permis leur obtention (voir par exemple Carroll et al 2016, Murray et Maga 2016, Kuzma 2016). Selon ces auteurs, imposer une évaluation réglementaire longue et coûteuse, en l'absence de risque établi scientifiquement, est injustifié. Une plante produite par des techniques de modification ciblée est potentiellement non distinguable d'une plante issue des techniques usuelles de création variétale. Elle ne présenterait donc aucun risque théorique, et devrait par conséquent échapper à toute réglementation; une simple déclaration devrait suffire. Le même raisonnement pourrait naturellement être étendu aux animaux. Une décision administrative allant dans ce sens a d'ores et déjà été prise aux USA. Un champignon (Agaricus bisporus) dont le gène de la polyphénol oxidase a été inactivé par CRISPR-Cas9 pour éviter le brunissement, a été autorisé aux USA par une décision de l'USDA en date du 13 avril 2016. Nul doute que d'autres exemples, végétaux ou animaux, suivront dans les semaines et mois à venir.

Par ailleurs, les techniques de modification ciblées sont susceptibles de ne laisser aucune trace détectable sur les génomes : la mutation « naturelle » d'un gène, et la reproduction à la base près de cette modification par CRISPR, pourraient ne pas être distinguables. Se pose alors la question de la diffusion « cachée ", délibérée (parce que cela pourrait procurer un avantage commercial temporaire) ou involontaire d'individus issus de ces techniques sur des territoires (ou dans des populations) qui continueraient pourtant à les réglementer ou les interdire. La gestion de ce type de situation pourrait être particulièrement difficile.

D'autres questionnements sont d'ordre éthique. A-t-on le droit de se substituer à la nature pour introduire des modifications au sein de génomes d'espèces domestiques, même si, d'un point de vue moléculaire, certaines de ces modifications peuvent être de même nature que celles apparaissant naturellement par mutation? Nombre de travaux, plus ou moins récents, illustrent bien la très grande complexité des mécanismes de régulation des phénomènes biologiques. Peut-on raisonnablement penser maîtriser l'ensemble des conséquences que peut potentiellement induire, chez un animal, la modification, même très précise, d'une (ou plusieurs) région(s) de son génome ? La réponse à ces questions implique nécessairement la prise en compte de considérations qui dépassent largement le seul cadre scientifique.

L'acceptabilité (la recevabilité par le citoyen-consommateur) des animaux issus de ce type de techniques est aussi une question très difficile à appréhender. Les débats concernant les OGM végétaux sont d'une grande complexité eux aussi, et parfois d'une grande violence. Il y a fort à parier que les débats que susciteront les perspectives de commercialisation d'animaux génétiquement modifiés seront au moins aussi difficiles. Même au sein de la communauté scientifique, dans des groupes d'experts tels que le Haut Conseil des Biotechnologies, le débat fait rage (voir la revue « Pour la Science », N464, juin 2016, pp 16-19). Si certains arguments avancés par différents groupes de recherche favorables aux OGM peuvent être équilibrés et recevables (voir par exemple la méta-analyse de Klümper et Qaim 2014), d'autres points de vue exprimés par des chercheurs plus réservés ou hostiles à ces techniques le sont tout autant (e.g. Jacobsen et al 2013). Une des difficultés tient au fait que le nombre de dimensions à considérer pour évaluer l'intérêt ou non de ces innovations est très important. Les questions relatives aux risques 
liés i) à la consommation de produits OGM pour la santé humaine, ou ii) à la dissémination de variétés OGM pour la biodiversité, par exemple, font partie des controverses : les avis rendus par certaines agences d'évaluation des risques sont contestés par certains groupes de recherche. Mais d'autres dimensions sont tout aussi importantes à considérer dans une perspective de gestion des risques, et font aussi l'objet d'appréciations parfois contradictoires. C'est le cas de l'évaluation des conséquences économiques, sociales, ou environnementales de l'utilisation de variétés OGM, qui, toutes, sont fonction de nombreux paramètres : la région considérée, le terme envisagé, la nature des modifications proposées, etc. Une argumentation classiquement développée par certains chercheurs (voir par exemple McColl et al 2013 ou Tizard et al 2016) est la suivante : une croissance très importante de la population humaine est attendue d'ici 2050 ; le chiffre de 9 milliards d'humains en 2050 est généralement avancé (voir Gerland et al 2014 pour plus de détails). Cette croissance démographique, accompagnée d'une augmen- tation de la consommation individuelle de produits animaux dans certaines régions (Chine notamment), induira une forte hausse de la demande alimentaire mondiale au cours des 30 prochaines années. La production alimentaire mondiale devra donc augmenter fortement elle aussi ( $\mathrm{de}+70 \%$ à $+100 \%$ selon les auteurs), et la seule façon de faire face à ce très important défi est de recourir aux biotechnologies (sous-entendu : les pratiques agricoles « conventionnelles » ne le permettront pas). D'autres avis, contradictoires, sont exprimés. Jacobsen et al 2013, par exemple, considèrent que, dans la mesure où c'est dans les pays du Sud que le besoin d'accroitre la production agricole sera particulièrement crucial dans les années à venir, et tout particulièrement en Afrique, des solutions «low-tech » doivent être privilégiées, parce qu'elles sont souvent plus efficaces et moins sujettes à l'échec.

Ces controverses rejoignent celles relatives au(x) modèle(s) d'agriculture(s) à promouvoir. C'est un euphémisme de dire que cette question fait toujours débat en France, ou en Europe. Encore plus à l'échelle mondiale, entre l'Union Européenne (UE) et les USA ${ }^{6}$, ou entre l'UE et la Chine, notamment.

\section{Conclusion}

Les méthodes permettant la procréation d'Animaux Génétiquement Modifiés (AGM) ont considérablement évolué ces dernières années. Le développement de lignées commerciales d'AGM dans certaines espèces l'élevage, pour la production de lait, d'œufs ou de viande destinés à la consommation humaine, pourrait être une réalité à assez court terme. Cela pose de multiples questions dont la communauté scientifique, et, plus largement, la société, devraient rapidement s'emparer.

\section{Remerciements}

Les auteurs remercient les relecteurs anonymes pour leur révision méticuleuse du manuscrit et leurs commentaires qui ont permis d'améliorer la qualité de ce texte.

\section{Références}

Amabile A., Migliara A., Capasso P., Biffi M., Cittaro D., Naldini L., Lombardo A., 2016. Inheritable silencing of endogenous genes by hit-and-run targeted epigenetic editing. Cell, 167, 219-232.

Bao Z., Cobb R.E., Zhao H., 2016. Accelerated genome engineering through multiplexing. Wiley Interdiscip. Rev. Syst. Biol., 8, 5-21.

Benfey T.J., 2016. Effectiveness of triploidy as a management tool for reproductive containment of farmed fish: Atlantic salmon (Salmo salar) as a case study. Rev. Aquac., 8, 264-282.

Bishop S.C., 2015. Genetic resistance to infections in sheep. Vet. Microbiol., 181, 2-7.

Bosselman R., Hsu R., Boggs T., Hu S., Bruszewski J., Ou S., Kozar L., Martin F., Green C., Jacobsen F., Nicolson M., Schultz J., Semon K., Rishell W., Stewart R., 1989. Germline transmission of exogenous genes in the chicken. Science, 243, 533-535.

Burkard C., Lillico S.G., Reid E., Jackson B., Mileham A.J., Ait-Ali T., Whitelaw C.B.A., Archibald A.L., 2017. Precision engineering for PRRSV resistance in pigs: Macrophages from genome edited pigs lacking CD163 SRCR5 domain are fully resistant to both PRRSV genotypes while maintaining biological function. PLoS Pathog., 13, e1006206.

Capecchi M., 1989. Altering the genome by homologous recombination. Science, 244, 1288 1292.
Carlson D.F., Lancto C.A., Zang B., Kim E.S., Walton M., Oldeschulte D., Seabury C., Sonstegard T.S., Fahrenkrug S.C., 2016. Production of hornless dairy cattle from genomeedited cell lines. Nature Biotechnol., 34, 479481.

Carroll D., Van Eenennaam A.L., Taylor J.F., Seger J., Voytas D.F., 2016. Regulate genomeedited products, not genome editing itself. Nature Biotechnol., 34, 477-479.

Caubet J.C., Wang J., 2011. Current understanding of egg allergy. Pediatr. Clin. North Am., $58,427-443$.

Chakrapani V., Patra S.K., Panda R.P., Rasal K. D., Jayasankar P., Barman H.K., 2016. Establishing targeted carp TLR22 gene disruption via homologous recombination using CRISPR/ Cas9. Dev. Comp. Immunol. 61, 242-247.

Champer J., Buchman A., Akbari O.S., 2016. Cheating evolution: engineering gene drives to manipulate the fate of wild populations. Nature Rev. Genet., 17, 146-159.

Chandrasegaran S., Carroll D., 2016. Origins of programmable nucleases for genome engineering. J. Mol. Biol., 428, 963-989.

Chen B., Gilbert L.A., Cimini B.A., Schnitzbauer J., Zhang W., Li G.W., Park J., Blackburn E.H., Weissman J.S., Qi L.S., Huang B., 2013. Dynamic imaging of genomic loci in living human cells by an optimized CRISPR/Cas system. Cell, 155, 1479-1491.
Chen S., Sanjana N.E., Zheng K., Shalem O. Lee K., Shi X., Scott D.A., Song J., Pan J.Q., Weissleder R., Lee H., Zhang F., Sharp P.A., 2015. Genome-wide CRISPR screen in a mouse model of tumor growth and metastasis. Cell, $160,1246-1260$

Chu V.T., Weber T., Wefers B., Wurst W. Sander S., Rajewsky K., Kuehn R., 2015. Increasing the efficiency of homology-directed repair for CRISPR-Cas9-induced precise gene editing in mammalian cells. Nature Biotechnol., $33,543-548$

Clark A., Bissinger P., Bullock D., Damak S., Wallace R., Whitelaw C., Yull F., 1994. Chromosomal position effects and the modulation of transgene expression. Reprod. Fertil. Dev., 6, 589-598.

Clausen R., Longo S.B., 2012. The tragedy of the commodity and the farce of AquAdvantage salmon (R). Dev. Change, 43, 229-251.

Cockett N.E., Smit M.A., Bidwell C.A., Segers K., Hadfield T.L., Snowder G.D., Georges M., Charlier C., 2005. The callipyge mutation and other genes that affect muscle hypertrophy in sheep. Genet. Select. Evol., 37, S65-S81.

Cong L., Ran F.A., Cox D., Lin S., Barretto R., Habib N., Hsu P.D., Wu X., Jiang W., Marraffini L.A., Zhang F., 2013. Multiplex genome engineering using CRISPR/Cas systems. Science, 339, 819-823. 
Daetwyler H.D., Capitan A., Pausch H., Stothard P., Van Binsbergen R., Brondum R.F., Liao X., Djari A., Rodriguez S.C., Grohs C., Esquerre D., Bouchez O., Rossignol M.N., Klopp C., Rocha D., Fritz S., Eggen A., Bowman P.J., Coote D., Chamberlain A.J., Anderson C., VanTassell C.P., Hulsegge I., Goddard M.E., Guldbrandtsen B., Lund M.S. Veerkamp R.F., Boichard D.A., Fries R., Hayes B.J., 2014. Whole-genome sequencing of 234 bulls facilitates mapping of monogenic and complex traits in cattle. Nature Genet., 46, 858865 .

Delanoue E., Roguet C., 2015. Acceptabilité sociale de l'élevage en France : recensement et analyse des principales controverses à partir des regards croisés de différents facteurs. INRA Prod. Anim., 28, 39-50.

Doench J.G., Fusi N., Sullender M., Hegde M., Vaimberg E.W., Donovan K.F., Smith I., Tothova Z., Wilen C., Orchard R., Virgin H. W., Listgarten J., Root D. ., 2016. Optimized sgRNA design to maximize activity and minimize off-target effects of CRISPR-Cas9. Nature Biotechnol., 34, 184-191.

Doeschl-Wilson A., Wilson A., Nielsen J., Nauwynck H., Archibald A., Ait-Ali T., 2016. Combining laboratory and mathematical models to infer mechanisms underlying kinetic changes in macrophage susceptibility to an RNA virus. BMC Syst. Biol., 10:101, DOI 10.1186/s12918-016-0345-5.

Doran T.J., Cooper C.A., Jenkins K.A., Tizard M.L. V., 2016. Advances in genetic engineering of the avian genome: "Realising the promise.” Transgenic Res., 25, 307-319.

Dorshorst B., 2014. Half of Holstein heifer calves could be polled by 2034. Progressive Dairyman (17 January, 2014). http://www.progressivedairy.com/topics/ai-breeding/half-ofholstein-heifer-calves-could-bepolled-by-2034.

Doudna J.A., Charpentier E., 2014. The new frontier of genome engineering with CRISPRCas9. Science, 346, 1077-1087.

Du S., Gong Z., Fletcher G., Shears M., King M., Idler D., Hew C., 1992. Growth enhancement in transgenic Atlantic salmon by the use of an all fish chimeric growth-hormone gene construct. Biotechnology, 10, 176-181.

Duchesne A., Grohs C., Michot P., Bertaud M., Boichard D., Floriot S., Capitan A., 2016. Du phénotype à la mutation causale : le cas des anomalies récessives bovines. In : Anomalies génétiques. Boichard D. (Ed). Dossier, INRA Prod. Anim., 29, 319-328

Edvardsen R.B., Leininger S., Kleppe L., Skaftnesmo K.O., Wargelius A., 2014. Targeted mutagenesis in Atlantic salmon (Salmo salar L.) using the CRISPR/Cas9 system induces complete knockout individuals in the F0 Generation. PLoS One, 9, e108622.

Egelie K.J., Graff G.D., Strand S.P., Johansen B., 2016. The emerging patent landscape of CRISPR-Cas gene editing technology. Nature Biotechnol., 34, 1025-1032.

Elsen J.M., Amigues Y., Schelcher F., Ducroca V., Andreoletti O., Eychenne F., Khang J.V.T., Poivey J.P., Lantier F., Laplanche J.L., 1999. Genetic susceptibility and transmission factors in scrapie: detailed analysis of an epidemic in a closed flock of Romanov. Arch. Virol., 144, 431-445.
Essalmani R., Soulier S., Besnard N., Hudrisier M., Costa Da Silva J., Vilotte J.L., 2000 Données de base sur la transgenèse. In Génétique moléculaire : principes et application aux populations animales. Bibé B., Ducos A., Gillet P., Le Roy P., Manfredi E., Mulsant P., Pinard-van der Laan M.H., Rogel-Gaillard C., Sellier P., Vaiman D., Yerle M., Farce M.H., Perez J.M. (Eds). Hors-série, INRA Prod Anim., 13, 181-186.

Estrela R., Cate J.H.D., 2016. Energy biotechnology in the CRISPR-Cas9 era. Curr. Opin. Biotechnol., 38, 79-84.

Fahrenkrug S.C., Blake A., Carlson D.F., Doran T., Van Eenennaam A., Faber D., Galli C., Gao Q., Hackett P.B., Li N., Maga E. A Muir W.M., Murray J.D., Shi D., Stotish R., Sullivan E., Taylor J.F., Walton M., Wheeler M., Whitelaw B., Glenn B.P., 2010. Precision genetics for complex objectives in animal agriculture. J. Anim. Sci., 88, 2530-2539.

Fujita T., Fujii H., 2013. Efficient isolation of specific genomic regions and identification of associated proteins by engineered DNAbinding molecule-mediated chromatin immunoprecipitation (enChIP) using CRISPR Biochem. Biophys. Res. Commun., 439, 132 136.

Gerland P., Raftery A.E., Sevcikova H., Li N. Gu D., Spoorenberg T., Alkema L., Fosdick B.K., Chunn J., Lalic N., Bay G., Buettner T. Heilig G.K., Wilmoth J., 2014. World population stabilization unlikely this century. Science, 346, 234-237.

Gilbert L.A., Larson M.H., Morsut L., Liu Z., Brar G.A., Torres S.E., Stern-Ginossar N., Brandman O., Whitehead E. H., Doudna J. A., Lim W. A., Weissman J. S., Qi L. S., 2013 CRISPR-Mediated modular RNA-guided regulation of transcription in eukaryotes. Cell, 154 442-451.

Gilbert L.A., Horlbeck M.A., Adamson B. Villalta J.E., Chen Y., Whitehead E.H. Guimaraes C., Panning B., Ploegh H.L., Bassik M.C., Qi L.S., Kampmann M., Weissman J.S 2014. Genome-scale CRISPR-mediated contro of gene repression and activation. Cell, 159, 647-661.

Golovan S.P., Meidinger R.G., Ajakaiye A., Cottrill M., Wiederkehr M.Z, Barney D.J. Plante C., Pollard J.W., Fan M.Z., Hayes M.A., Laursen J., Hjorth J.P., Hacker R.R., Phillips J.R., Forsberg C.W., 2001. Pigs expressing salivary phytase produce low-phosphorus manure. Nature Biotechnol., 19, 741-745.

Goodwin S., McPherson J.D., McCombie W.R., 2016. Coming of age: ten years of nextgeneration sequencing technologies. Nature Rev. Genet., 17, 333-351.

Gordon J., Ruddle F., 1981. Integration and stable germ line transmission of genes injected into mouse pronuclei. Science, 214, 1244-1246.

Grisart B., Coppieters W., Farnir F., Karim L., Ford C., Berzi P., Cambisano N., Mni M., Reid S., Simon P., Spelman R., Georges M., Snel R., 2002. Positional candidate cloning of a QTL in dairy cattle: Identification of a missense mutation in the bovine DGAT1 gene with major effect on milk yield and composition. Genome Res., 12, 222-231.

Grobet L., Martin L.J.R., Poncelet D., Pirottin D., Brouwers B., Riquet J., Schoeberlein A.
Dunner S., Menissier F., Massabanda J., Fries R., Hanset R., Georges M., 1997. A deletion in the bovine myostatin gene causes the doublemuscled phenotype in cattle. Nature Genet., 17, 71-74.

Guy G., Fortun-Lamothe L., Benard G., Fernandez X., 2013. Natural induction of spontaneous liver steatosis in Greylag Landaise geese (Anser anser). J. Anim. Sci., 91, 455 464.

Haeussler M., Concordet J.P., 2016. Genome editing with CRISPR-Cas9, can it get any better? J. Genet. Genomics, 43, 239-250.

Hammer R., Pursel V., Rexroad C., Wall R., Bolt D., Ebert K., Palmiter R., Brinster R., 1985. Production of transgenic rabbits, sheep and pigs by Microinjection. Nature, 315, 680683 .

Hammond A., Galizi R., Kyrou K., Simoni A., Siniscalchi C., Katsanos D., Gribble M., Baker D., Marois E., Russell S., Burt A., Windbichler N., Crisanti A., Nolan T., 2016. A CRISPRCas9 gene drive system-targeting female reproduction in the malaria mosquito vector Anopheles gambiae. Nature Biotechnol., 34 78-83.

Houdebine L.M., 1998. La transgenèse animale et ses applications. In : Biotechnologies animales. Grosclaude F. (Ed). Numéro special, INRA Prod. Anim., 11, 81-94.

Houdebine L.M., 2005. Use of transgenic animals to improve human health and animal production. Reprod. Domest. Anim., 40, 269-281.

Hsu P.D., Lander E.S., Zhang F., 2014. Development and applications of CRISPRCas9 for genome engineering. Cell, 157, 12621278

Hwang W.Y., Fu Y., Reyon D., Maeder M.L., Kaini P., Sander J.D., Joung J.K., Peterson R.T., Yeh J.R.J., 2013. Heritable and precise zebrafish genome editing using a CRISPR-Cas system. PLoS One, 8, e68708.

Jacobsen S.E., Sorensen M., Pedersen S.M., Weiner J., 2013. Feeding the world, genetically modified crops versus agricultural biodiversity. Agron. Sustain. Dev., 33, 651-662.

Jenko J., Gorjanc G., Cleveland M.A., Varshney R.K., Whitelaw C.B.A., Woolliams J.A., Hickey J.M., 2015. Potential of promotion of alleles by genome editing to improve quantitative traits in livestock breeding programs. Genet. Sel. Evol., 47, 55.

Jinek M., Chylinski K., Fonfara I., Hauer M., Doudna J. A., Charpentier E., 2012. A Programmable dual-RNA-guided DNA endonuclease in adaptive bacterial immunity. Science, 337, 816-821.

Jo Y.I., Suresh B., Kim H., Ramakrishna S. 2015. CRISPR/Cas9 system as an innovative genetic engineering tool: Enhancements in sequence specificity and delivery methods Biochim. Biophys. Acta-Rev. Cancer, 1856 , 234-243.

Kearns N.A., Genga R.M.J., Enuameh M.S. Garber M., Wolfe S.A., Maehr R., 2014. Cas9 effector-mediated regulation of transcription and differentiation in human pluripotent stem cells. Development, 141, 219-223.

Kemper K.E., Goddard M.E., 2012. Understanding and predicting complex traits: 
knowledge from cattle. Hum. Mol. Genet., 21, R45-R51.

Khatodia S., Bhatotia K., Passricha N., Khurana S.M.P., Tuteja N., 2016. The CRISPR/Cas genome-editing tool: application in improvement of crops. Front. Plant Sci., 7, 506.

Kleinstiver B.P., Pattanayak V., Prew M.S., Tsai S.Q., Nguyen N.T., Zheng Z., Joung J.K., 2016. High-fidelity CRISPR-Cas9 nucleases with no detectable genome-wide off-target effects. Nature, 529, 490-495.

Kluemper W., Qaim M., 2014. A Meta-analysis of the impacts of genetically modified crops. PLoS One, 9, e111629.

Komor A.C., Kim Y.B., Packer M.S., Zuris J.A., Liu D.R., 2016. Programmable editing of a target base in genomic DNA without doublestranded DNA cleavage. Nature, 533, 420-424. Komor A.C., Badran A.H., Liu D.R., 2017. CRISPR-based technologies for the manipulation of eukaryotic genomes. Cell, 168, 20-36.

Konermann S., Brigham M.D., Trevino A.E., Joung J., Abudayyeh O.O., Barcena C., Hsu P.D., Habib N., Gootenberg J.S., Nishimasu H., Nureki O., Zhang F., 2015. Genome-scale transcriptional activation by an engineered CRISPR-Cas 9 complex. Nature, 517, 583U332.

Kungulovski G., Jeltsch A., 2016. Epigenome editing: state of the art, concepts, and perspectives. Trends Genet., 32, 101-113.

Kuzma J., 2016. Reboot the debate on genetic engineering. Nature, 531, 165-167.

Lander E.S., 2016. The heroes of CRISPR. Cell, 164, 18-28.

Ledford H., 2015a. Crispr, the disruptor. Nature, 522, 20-24.

Ledford H., 2015b. Transgenic salmon leaps to the dinner table. Nature, 527, 417-418.

Ledford H., 2016. Bitter fight over CRISPR patent heats up. Nature, 529, 265-265.

Li M., Yang H., Zhao J., Fang L., Shi H., Li M., Sun Y., Zhang X., Jiang D., Zhou L., Wang D., 2014. Efficient and heritable gene targeting in tilapia by CRISPR/Cas9. Genetics, 197, 591599.

Lifschitz C., Szajewska H., 2015. Cow's milk allergy, evidence-based diagnosis and management for the practitioner. Eur. J. Pediatr., 174, 141-150.

Liu X., Wang Y., Tian Y., Yu Y., Gao M., Hu G., Su F., Pan S., Luo Y., Guo Z., Quan F., Zhang Y., 2014. Generation of mastitis resistance in cows by targeting human lysozyme gene to beta-casein locus using zinc-finger nucleases. Proc. R. Soc. B-Biol. Sci., 281, 20133368.

Liu X.S., Wu H., Ji X., Stelzer Y., Wu X., Czauderna S., Shu J., Dadon D., Young R.A., Jaenisch R., 2016. Editing DNA methylation in the mammalian genome. Cell, 167, 233-247.

Lucht J.M., 2015. Public acceptance of plant biotechnology and GM Crops. Viruses-Basel, 7, 4254-4281.

Lyall J., Irvine R.M., Sherman A., McKinley T.J., Nunez A., Purdie A., Outtrim L., Brown
I.H., Rolleston-Smith G., Sang H., Tiley L., 2011. Suppression of avian influenza transmission in genetically modified chickens. Science, 331, 223-226.

Ma H., Naseri A., Reyes-Gutierrez P., Wolfe S.A., Zhang S., Pederson T., 2015. Multicolor CRISPR labeling of chromosomal loci in human cells. Proc. Natl. Acad. Sci. U. S. A., 112, 3002-3007.

Maeder M.L., Gersbach C.A., 2016. Genomeediting technologies for gene and cell therapy. Mol. Ther., 24, 430-446.

Mali P., Yang L., Esvelt K.M., Aach J., Guell M., DiCarlo J.E., Norville J.E., Church G.M., 2013. RNA-guided human genome engineering via Cas9. Science, 339, 823-826.

Mandegar M.A., Huebsch N., Frolov E.B., Shin E., Truong A., Olvera M.P., Chan A. H., Miyaoka Y., Holmes K., Spencer C.I., Judge L.M., Gordon D.E., Eskildsen T.V., Villalta J.E., Horlbeck M.A., Gilbert L.A., Krogan N.J., Sheikh S.P., Weissman J.S., Qi L. S., So P.L., Conklin B.R., 2016. CRISPR interference efficiently induces specific and reversible gene silencing in human iPSCs. Cell Stem Cell, 18, 541-553.

Marraffini L.A., 2015. CRISPR-Cas immunity in prokaryotes. Nature, 526, 55-61.

Maruyama T., Dougan S.K., Truttmann M.C., Bilate A.M., Ingram J.R., Ploegh H.L., 2015. Increasing the efficiency of precise genome editing with CRISPR-Cas9 by inhibition of nonhomologous end joining. Nature Biotechnol., 33, 538-542.

Maxmen A., 2015. Three technologies that changed genetics. Nature, 528, S2-S3.

McColl K.A., Clarke B., Doran T.J., 2013 Role of genetically engineered animals in future food production. Aust. Vet. J., 91, 113-117.

McCreath K.J., Howcroft J., Campbell K.H.S. Colman A., Schnieke A.E., Kind A.J., 2000 Production of gene-targeted sheep by nuclear transfer from cultured somatic cells. Nature, 405, 1066-1069.

Medugorac I., Seichter D., Graf A., Russ I., Blum H., Goepel K.H., Rothammer S. Foerster M., Krebs S., 2012. Bovine polledness - an autosomal dominant trait with allelic heterogeneity. PLoS One, 7, e39477.

Menchaca A., Anegon I., Whitelaw C.B.A. Baldassarre H., Crispo M., 2016. New insights and current tools for genetically engineered (GE) sheep and goats. Theriogenology, 86 160-169.

Milan D., Jeon J.T., Looft C., Amarger V., Robic A., Thelander M., Rogel-Gaillard C., Paul S., Iannuccelli N., Rask L., Ronne H., Lundstrom K., Reinsch N., Gellin J., Kalm E., Le Roy P., Chardon P., Andersson L., 2000. A mutation in PRKAG3 associated with excess glycogen content in pig skeletal muscle. Science, 288, 1248-1251.

Mou C., Pitel F., Gourichon D., Vignoles F., Tzika A., Tato P., Yu L., Burt D.W., Bed'hom B., Tixier-Boichard M., Painter K.J., Headon D.J., 2011. Cryptic patterning of avian skin confers a developmental facility for loss of neck feathering. PLoS. Biol., 9, e1001028.

Murray J.D., Maga E.A., 2016. A new paradigm for regulating genetically engineered ani- mals that are used as food. Proc. Natl. Acad. Sci. U. S. A., 113, 3410-3413.

Nelles D.A., Fang M.Y., O’Connell M.R., Xu J.L., Markmiller S.J., Doudna J.A., Yeo G.W., 2016 Programmable RNA tracking in live cells with CRISPR/Cas9. Cell, 165, 488-496.

Nelson C.E., Gersbach C.A., 2016. Engineering delivery vehicles for genome editing. Annu. Rev. Chem. Biomol. Eng., 7, 637-662.

Nicholas F.W., Hobbs M., 2014. Mutation discovery for Mendelian traits in non-laboratory animals: a review of achievements up to 2012. Anim. Genet., 45, 157-170.

Niemann H., Petersen B., 2016. The production of multi-transgenic pigs, update and perspectives for xenotransplantation. Transgenic Res., 25, 361-374.

Nishijima K., Iijima S., 2013. Transgenic chickens. Dev. Growth Diff., 55, 207-216.

Ochiai H., Sugawara T., Yamamoto T., 2015. Simultaneous live imaging of the transcription and nuclear position of specific genes. Nucleic Acids Res., 43, e127.

Oishi I., Yoshii K., Miyahara D., Kagami H., Tagami T., 2016. Targeted mutagenesis in chicken using CRISPR/Cas9 system. Sci. Rep., 6, 23980 .

Paquet D., Kwart D., Chen A., Sproul A., Jacob S., Teo S., Olsen K.M., Gregg A., Noggle S., Tessier-Lavigne M., 2016. Efficient introduction of specific homozygous and heterozygous mutations using CRISPR/Cas9. Nature, 533, 125-129.

Park T.S., Lee H.J., Kim K.H., Kim J.S., Han J.Y., 2014. Targeted gene knockout in chickens mediated by TALENs. Proc. Natl. Acad. Sci. U. S. A., 111, 12716-12721.

Ran F.A., Hsu P.D., Wright J., Agarwala V., Scott D.A., Zhang F., 2013a. Genome engineering using the CRISPR-Cas9 system. Nature Protoc., 8, 2281-2308.

Ran F.A., Hsu P.D., Lin C.Y., Gootenberg J.S., Konermann S., Trevino A.E., Scott D.A., Inoue A., Matoba S., Zhang Y., Zhang F., 2013 b. Double nicking by RNA-guided CRISPR Cas9 for enhanced genome editing specificity. Cell, $155,479-480$.

Ran F.A., Cong L., Yan W.X., Scott D.A., Gootenberg J.S., Kriz A.J., Zetsche B., Shalem O., Wu X., Makarova K.S., Koonin E.V., Sharp P.A., Zhang F., 2015. In vivo genome editing using Staphylococcus aureus Cas9. Nature, 520, 186-U98.

Reardon S., 2016. The Crispr Zoo. Nature, 531, 160-163.

Riggio V., Portolano B., 2015. Genetic selection for reduced somatic cell counts in sheep milk: A review. Small Rum. Res., 126, 33-42.

Rupp R., Senin P., Sarry J., Allain C., Tasca C., Ligat L., Portes D., Woloszyn F., Bouchez O., Tabouret G., Lebastard M., Caubet C., Foucras G., Tosser-Klopp G., 2015. A point mutation in suppressor of cytokine signalling 2 (Socs2) increases the susceptibility to inflammation of the mammary gland while associated with higher body weight and size and higher milk production in a sheep model. PLoS Genet., 11, e1005629. 
Salter D., Crittenden L., 1989. Artificial insertion of a dominant gene for resistance to avianleukosis virus into the germ line of the chicken. Theor. Appl. Genet., 77, 457-461

Sato M., Ohtsuka M., Watanabe S., Gurumurthy C.B., 2016. Nucleic acids delivery methods for genome editing in zygotes and embryos: the old, the new, and the old-new. Biol. Direct, 11, 16.

Schusser B., Collarini E.J., Yi H., Izquierdo S.M., Fesler J., Pedersen D., Klasing K.C., Kaspers B., Harriman W.D., Lavoir M.C. van de, Etches R.J., Leighton P.A., 2013. Immunoglobulin knockout chickens via efficient homologous recombination in primordial germ cells. Proc. Natl. Acad. Sci. U. S. A., 110, 20170-20175.

Sender G., Korwin-Kossakowska A., Pawlik A., Hameed K.G.A., Oprzadek J., 2013. Genetic basis of mastitis resistance in dairy cattle - a review. Ann. Anim. Sci., 13, 663-673.

Shalem O., Sanjana N. E., Zhang F., 2015. High-throughput functional genomics using CRISPR-Cas9. Nat. Rev. Genet., 16, 299-311.

Song Y., Cui C., Zhu H., Li Q., Zhao F., Jin Y., 2015. Expression, purification and characterization of zinc-finger nuclease to knockout the goat beta-lactoglobulin gene. Protein Expr. Purif., 112, 1-7.

Tabashnik B.E., Brevault T., Carrière Y., 2013. Insect resistance to $\mathrm{Bt}$ crops: lessons from the first billion acres. Nature Biotechnol., 31, 510521.

Tan W., Carlson D.F., Lancto C.A., Garbe J.R., Webster D.A., Hackett P.B., Fahrenkrug S.C., 2013. Efficient nonmeiotic allele introgression in livestock using custom endonucleases. Proc. Natl. Acad. Sci. U. S. A., 110, 16526-16531.

Tan W., Proudfoot C., Lillico S.G., Whitelaw C.B.A., 2016. Gene targeting, genome editing: from Dolly to editors. Transgenic Res., 25, 273-287.

Tizard M., Hallerman E., Fahrenkrug S. Newell-McGloughlin M., Gibson J., Loos F. de, Wagner S., Laible G., Han J.Y., D’Occhio M., Kelly L., Lowenthal J., Gobius K., Silva P., Cooper C., Doran T., 2016. Strategies to enable the adoption of animal biotechnology to sustainably improve global food safety and security. Transgenic Res., 25, 575-595.
Tyack S. G., Jenkins K.A., O’Neil T.E., Wise T.G., Morris K.R., Bruce M.P., McLeod S., Wade A.J., McKay J., Moore R.J., Schat K.A., Lowenthal J.W., Doran T.J., 2013. A new method for producing transgenic birds via direct in vivo transfection of primordial germ cells. Transgenic Res., 22, 1257-1264.

Van Breedam W., Delputte P.L., Van Gorp H., Misinzo G., Vanderheijden N., Duan X., Nauwynck H.J., 2010. Porcine reproductive and respiratory syndrome virus entry into the porcine macrophage. J. Gen. Virol., 91, 16591667

Van de Lavoir M.C. van de, Diamond J.H., Leighton P.A., Mather-Love C., Heyer B.S., Bradshaw R., Kerchner A., Hooi L.T., Gessaro T.M., Swanberg S.E., Delany M.E., Etches R.J., 2006. Germline transmission of genetically modified primordial germ cells. Nature, 441 766-769.

Vinet A., Drouilhet L., Bodin L., Mulsant P, Fabre S., Phocas F., 2012. Genetic control of multiple births in low ovulating mammalian species. Mamm. Genome, 23, 727-740.

Von Borell E. von, Baumgartner J., Giersing M., Jaeggin N., Prunier A., Tuyttens F. a. M. Edwards S. A., 2009. Animal welfare implications of surgical castration and its alternatives in pigs. Animal, 3, 1488-1496.

Wang T., Birsoy K., Hughes N.W., Krupczak K.M., Post Y., Wei J.J., Lander E.S., Sabatin D.M., 2015. Identification and characterization of essential genes in the human genome. Science, 350, 1096-1101.

Wang H., La Russa M., Qi L.S., 2016 CRISPR/Cas9 in genome editing and beyond. Annu. Rev. Biochem., 85, 227-264.

Wargelius A., Leininger S., Skaftnesmo K.O., Kleppe L., Andersson E., Taranger G.L. Schulz R.W., Edvardsen R.B., 2016. Dnd knockout ablates germ cells and demonstrates germ cell independent sex differentiation in Atlantic salmon. Sci. Rep., 6, 21284.

Wei J., Wagner S., Lu D., Maclean P., Carlson D.F., Fahrenkrug S. C., Laible G., 2015. Efficient introgression of allelic variants by embryo-mediated editing of the bovine genome. Sci. Rep., 5, 11735.
Whitelaw C.B.A., Sheets T.P., Lillico S.G., Telugu B.P., 2015. Engineering large animal models of human disease. J. Pathol., 238, $247-$ 256.

Whitworth K.M., Lee K., Benne J.A., Beaton B.P., Spate L.D., Murphy S.L., Samuel M.S., Mao J., O'Gorman C., Walters E.M., Murphy C.N., Driver J., Mileham A., McLaren D., Wells K.D., Prather R.S., 2014. Use of the CRISPR/Cas9 system to produce genetically engineered pigs from in vitro-derived oocytes and embryos. Biol. Reprod., 91, 78 .

Whitworth K.M., Rowland R.R.R., Ewen C.L., Trible B.R., Kerrigan M.A., Cino-Ozuna A.G., Samuel M.S., Lightner J.E., McLaren D.G., Mileham A.J., Wells K.D., Prather R.S., 2016. Gene-edited pigs are protected from porcine reproductive and respiratory syndrome virus. Nature Biotechnol., 34, 20-22.

Xiong K., Li S., Zhang H., Cui Y., Yu D., Li Y., Sun W., Fu Y., Teng Y., Liu Z., Zhou X., Xiao P., Li J., Liu H., Chen J., 2013. Targeted editing of goat genome with modular-assembly zinc finger nucleases based on activity prediction by computational molecular modeling. Mol. Biol. Rep., 40, 4251-4256.

Yu S., Luo J., Song Z., Ding F., Dai Y., Li N., 2011. Highly efficient modification of beta-lactoglobulin (BLG) gene via zinc-finger nucleases in cattle. Cell Res., 21, 1638-1640.

Zetsche B., Gootenberg J.S., Abudayyeh O.O., Slaymaker I.M., Makarova K.S., Essletzbichler P., Volz S.E., Joung J., Oost J. van der, Regev A., Koonin E.V., Zhang F., 2015. Cpfl Is a single RNA-guided endonuclease of a Class 2 CRISPR-Cas System. Cell, 163, 759-771.

Zhang P., Hayat M., Joyce C., Gonzalezvillasenor L., Lin C., Dunham R., Chen T., Powers D., 1990. Gene-transfer, expression and inheritance of SV-Rainbow trout-GH cDNA. Mol. Reprod. Dev., 25, 3-13.

Zhang F., 2015. Development and applications of CRISPR-Cas9 for genome manipulations. FASEB J., 29, 214-221.

Zinsstag J., Schelling E., Waltner-Toews D., Tanner M., 2011. From "one medicine" to "one health" and systemic approaches to health and well-being. Prev. Vet. Med., 101, 148-156.

\section{Résumé}

L'avènement des nucléases programmables, et de CRISPR-Cas9 en particulier, constitue une réelle rupture technologique dans le domaine de l'ingénierie génétique. Le principe de ces méthodes est relativement simple. Il consiste en premier lieu à générer des cassures double-brin au niveau de régions très précises d'une séquence cible (ADN d'une cellule somatique, germinale, embryonnaire, iPS...). Ces cassures sont ensuite réparées par des mécanismes cellulaires pouvant conduire à l'inactivation des régions modifiées (knock-out, ou KO), ou à l'insertion, par recombinaison homologue, d'un fragment de séquence modèle apporté à la cellule (knock-in, ou KI). Les domaines d'application de ces techniques sont très nombreux : recherche fondamentale, thérapie génique, ingénierie écologique, biotechnologies industrielles, agriculture, etc. Elles ont d'ores et déjà été utilisées à de multiples reprises dans les espèces animales d'élevage. Des exemples d'applications visant à améliorer la santé des animaux (induction de résistances pour des maladies infectieuses à fort impact économique, et/ou à fort potentiel zoonotique), à éviter des pratiques d'élevage compromettant le bien-être animal (écornage, élimination systématique de poussins mâles), ou à modifier les produits (lait, œufs, viande) dans le but d'améliorer leur valeur santé (réduction des allergies), ou nutritionnelle, sont présentés. Le déploiement de ces méthodes soulève de multiples questions (techniques, réglementaires, économiques, éthiques...) qui sont discutées. 
Abstract

Genome Editing: what impact for farm animal species?

The advent of designer nucleases, especially CRISPR-Cas9, is providing a real breakthrough in genome editing technology. The principle is relatively simple. Double-strand breaks (DSB) are accurately produced on selected target DNA sequences from somatic, germinal, embryonic or iPS cells. These DSB are then repaired by non-homologous end-joining, resulting in inactivation (knock-out) of the targeted sequence(s), or by inserting a specific DNA fragment (template) through homologous recombination (knock-in). These technologies can be used in multiples domains, including fundamental research, gene therapy, ecological engineering, biotechnologies or agriculture. Many applications involving farm-animal species have already been published. Examples are presented of research projects aimed at improving animal health (acquisition of resistance to major infections and/or zoonotic diseases), avoiding controversial breeding practices (dehorning, elimination of male chicks), and improving the health impact (reduction of allergies) and/or nutritional values of animal products (milk, eggs, meat). Numerous questions raised by the use of CRISPR technology (techniques, regulation, economics, ethics...) are discussed.

DUCOS A., BED’HOM B., ACLOQUE H., PAIN B., 2017. Modifications ciblées des génomes : apports et impacts pour les espèces d'élevage. INRA Prod. Anim., 30, 3-18. 
